البنية العاملية للذكاء السائل لدى طلاب كلية التربية جامعه الفيوم

\author{
إعـــداد \\ د.عائشة على رف عطية

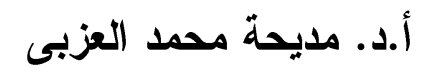 \\ استاذ علم النفس التزبوى التزئ \\ كلية التزبية - جامعه الفيوم \\ د. وسام عبد المعطى محمد \\ مدرس علم النفس التزبوى \\ كلية التربية- جامعة الفيوم
}

مجلة الاراسات التربوية والانسانية ـ كلية التربية ـ جامعة دمنهور المجلد السادس -العدد الأول- لسنة 2014 
البنية العاملية للاكاء السائل لاى طلاب كلية الثربية جامعة الفيوم د. عائشة على رف عطية 


\section{البنية العاملية للأكاء السائل لدى طلاب كلية التربية جامعة الفيوم}

د.عائشة على رف عطية - د. وسام عبد المعطى محمد

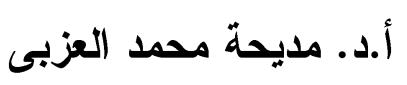

الملخص

هدفت الدراسة الحالية إلى التعرف على المكونات العاملية للذكاء الســائل

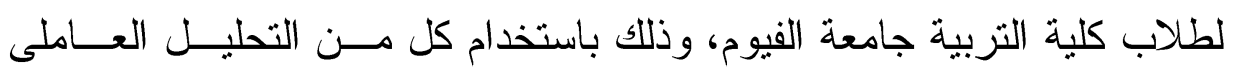

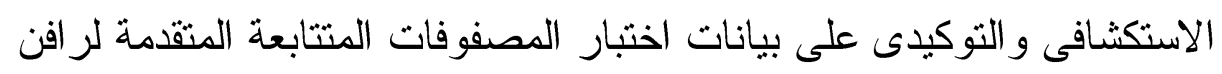
Raven's Advanced Progressive Matrices 320 طالب وطالبة من طلاب الجامعــة(86\% إناث).وأظهرت نتائج التحليل

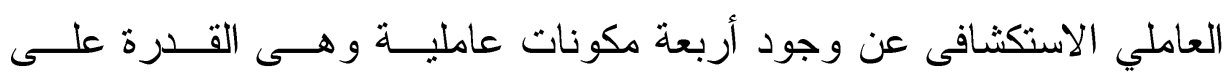

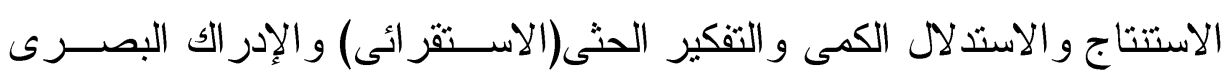

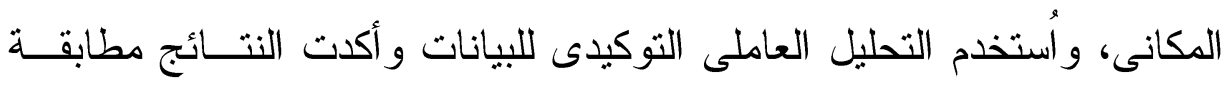

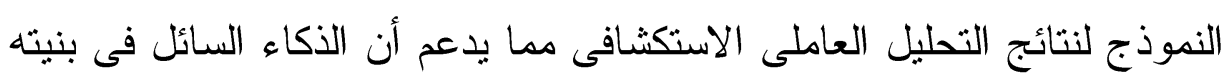
لا يقتصر على عامل واحد وإنما هو متعدد العوامل.

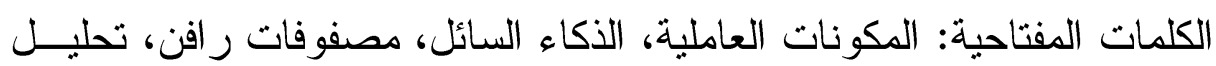
عاملى، تحليل توكيدى، البصرى المكانى. 


\section{Abstract}

The current study aimed to investigate the components of fluid intelligence as measured by Raven's Advanced Progressive Matrices Test (APM. The test was administered to a sample of 320 university students (18-22 years old, 86\% female) in Fayoum University, Egypt. Exploratory and confirmatory factor analysis showed the loadings of the test items on four factors, which were identified as the Deductive , Quantitative Reasoning, Induction and Visuospatial Ability. Results supported the view that fluid intelligence is a multidimensional ability.
\end{abstract}

Key words: Fluid Intelligence, general ability, Components Factorial, Raven Matrices, Confirmatory, Visuospatial, Factor Analyses 
يعد الذكاء السائل لب جميع القدرات العقلية، لذا فقـــــــــل اهتمـــام

الكثيرين من المختصين فى علم النفس بل و العامة أيضا، وقد أهتم علماء النفس بدر اسـة مفهومه و التعمق فيه، وذلك لما لهذا الموضوع مــن أهميــة قصـــوى تتعكس على الكثير من المجالات و الجوانب الاجتماعية و التعليمبة والتربوية بل

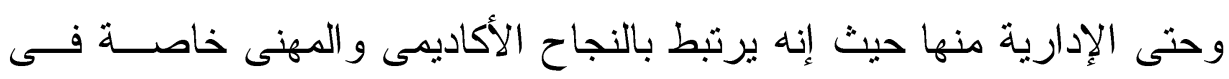
المو اقف الجديدةGottfredson,1997، بينما أهتم العامة بمفهوم الذكاء لما يتوقــع ئح أن يحققه لهم من مردود سو اء على المستوى النفسي أو الاجتماعي أو العملي

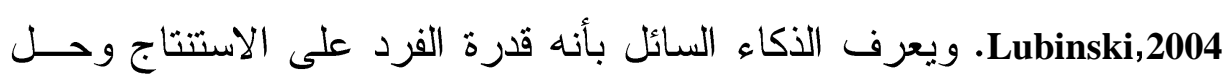
المشكلات الجديدة و المجردة بشكل مستقل عن الخبرات الســابقة و المهــار ات و المعارف المكتسبة Jaeggi, Buschkuehl, 2013 كما بعتبر قدرة عقلية معقـدة

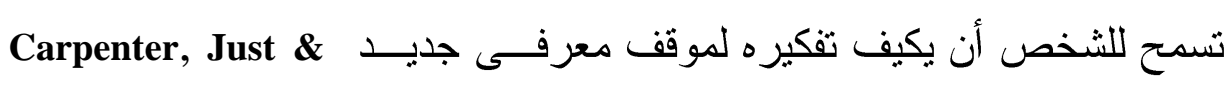
404. ويقاس الذكاء السائل بعدد من المقاييس النفسية وذلك من Shell, 1990 ,p. أهمها مصفوفات ر افن المتتابعـــة بنوعيهــا القياسـى Standard Progressive Matrices(SPM) قياس الذكاء السائل و يعتبر النسخة المتقدمة من مصفوفات ر افن و المناسـبـة Coloured Progressive لاب الجامعة، وكذلك المصفوفات المتتابعة الملونة Matrices(CPM) الثقافةهو هذه الاختبار ات لا تتطلب فقط القدرة على الاستنتاج ولكن تتطلب ايضا القدرة على حل المشكلات التباعدية، وبصيرة هائلة، و التحكم فى الاستر اتجيات

المناسبة لحل المشكلة 246.

ولقد اهتمت العديد من الدراسات بالتعرف على مكونات الذكاء الســائل وماهيته، وذللك من خلال معرفة البناء العاملى له وما إذا كان يمثل بعداً واحداً أو يشتمل على أكثر من بعد. وفى هذا نشأ افتر اضين الأول مؤداه أن الــذكاء 
السائل بعد واحد بما يتلاءم مع صدق الاختبار وصلاحيته لقياس الذكاء السائل

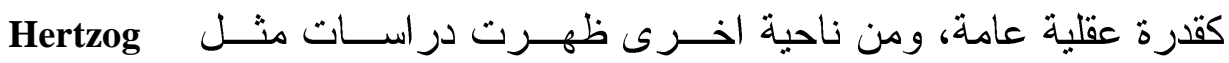
\&Carter, 1988 ; Van der Ven \& Ellis, 2000, الذكاء السائل و التى اعتمدت على تحليليها على مقــاييس النســخة القياســية

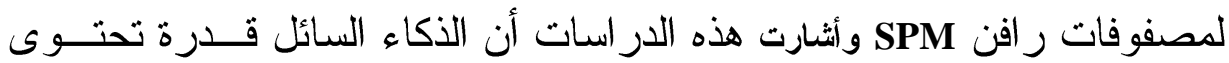

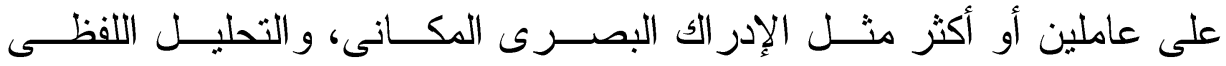
و الجشطلت.

ومن هنا وجد تعارض كبير بين وجهات النظر المختلفة حول البناء

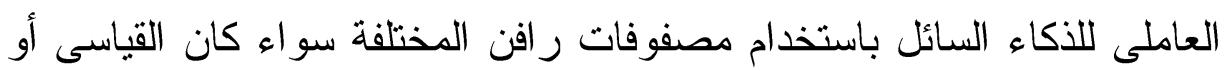

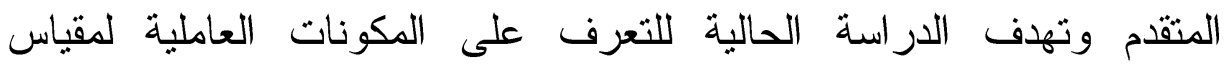
المصفوفات المتتابعة المتقدم لرافن، حيث لم تتتاوله أى دراسة عربية أو لى

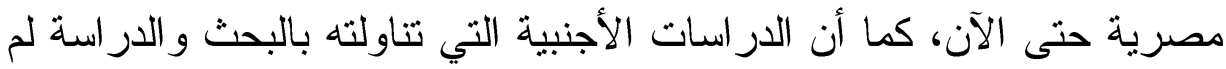
تتفق على بناء عاملى واحد. مشكية الار اسية

إن دراسة العو امل المكونة لأي قدرة هو جوهر اهتمام علماء النفس، لأن

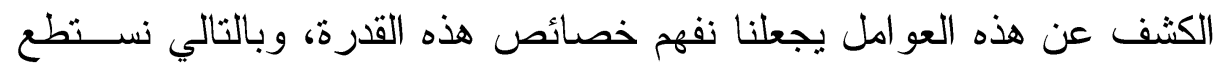
توظيفها التوظيف الأمثل في جميع المجالات، و نستطيع الرد علــى الســـؤال القائل "ما هي مكونات هذه القدرة" لوبه وتحددت مشكلة البحث الحالى فى الكثف عن المكونات العاملية للــــكاء

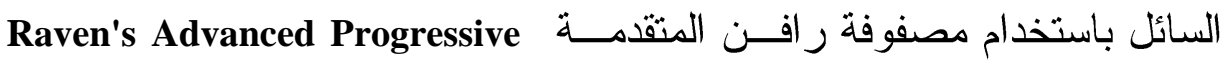
: من خلال الإجابة عن السؤال التالى (APM)Matrices ما المكونات العاملية للذكاء السائل لدى طلاب كلية التربية جامعة الفيوم ؟ 


\section{هدف الار اسية وأهميتها:}

1.التعرف على المكونات العاملية للاككاء السائل باستخدام اختبار

المصفوفات المتتابعة المثقدمة لر افن.

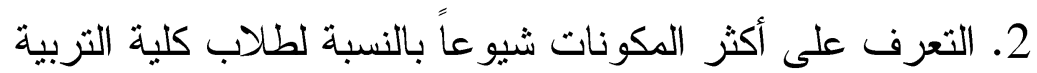

جامعة الفيوم.

3.إن تحديد مكونات الذكاء السائل يساعدنا فى عمل بر امج ودور ات

تدريبية لتنمية هذه المكونات لدى طلاب الجامعة.

حدود الدراسة :

تقتصر الدراسة الحالية على عينة من طلاب كلية التربية جامعة الفيوم فى لعى

$$
\text { مصطلحات الادر اسةة: 2012-2013 }
$$

\section{Fluid Intelligence الأكاء السائل}

قدرة الفرد على التعامل مع المو اقف الجديدة التى لم يو اجها مــن قبــل،

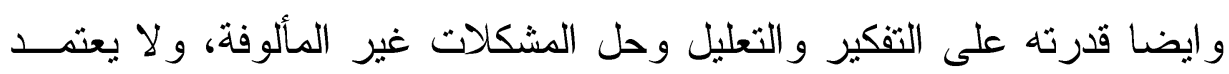

Stepankova et al.,2013 على الخبرة السابقة.

ويعرف اجر ائياً بالدرجة التى يحصل عليها الطالب فى اختبار مصفوفات رافن

$$
\text { المتقدمة وتتزو اح من (0 الى } 36 \text { درجة) }
$$


الإطار النظرى

يعتبر الذكاء السائل مؤشراً حقيقياً للنجاح التعليمى، فهو المســئول عـن حـلـ

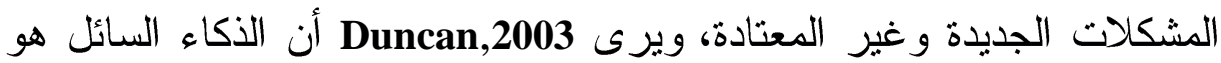

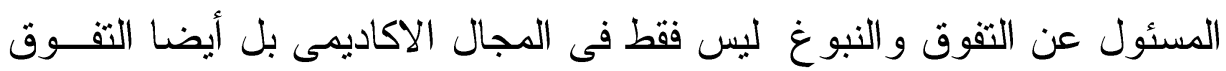

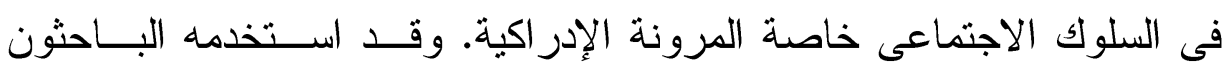
بمر ادفات عدة منها الذكاء غير اللفظى، و القدرة الاستدلالية و الذكاء العام وكلها

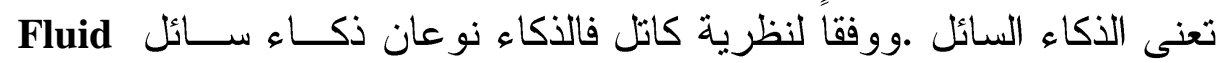
Intelligence يعني المعرفة المكتسبة، ويشير إلى المعارف و المهارات التي تتأثر بشكل قوي

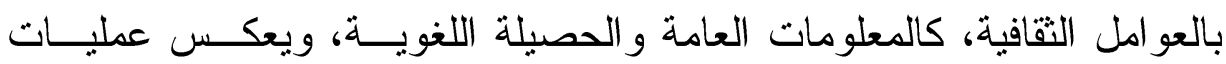

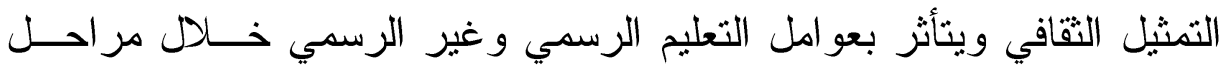

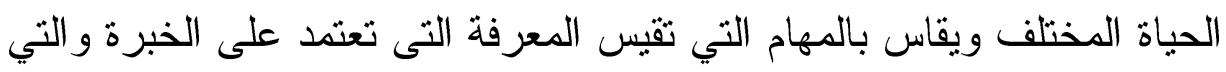

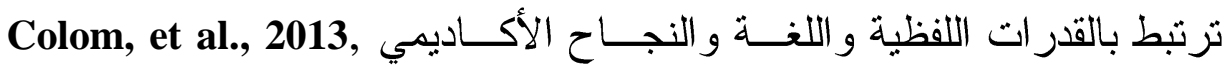

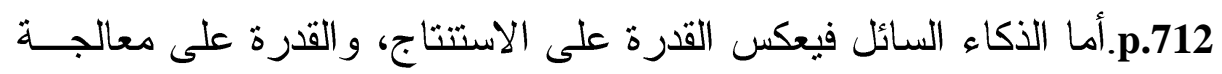
المعلومات مثل إيجاد التشابه الوظيفي و التتاظر بين سلسلة من الحروف مــن اهن

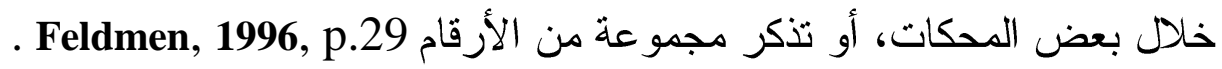

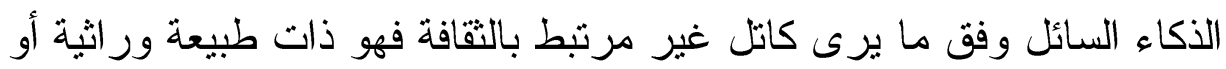

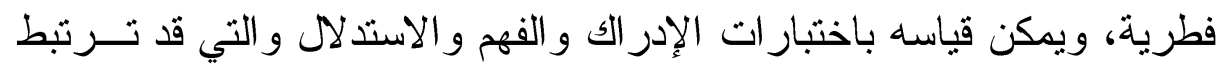

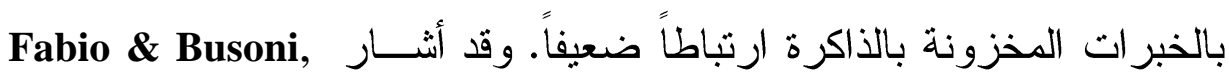
2007 إلى أن الذكاء السائل يقاس باختبار المصفوفات المتتابعة لر افن، ويتــأثر

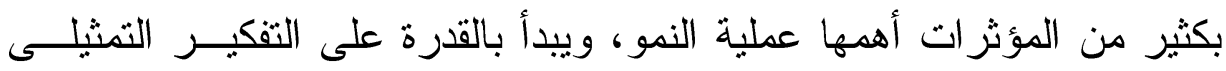

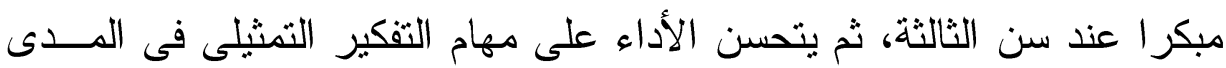

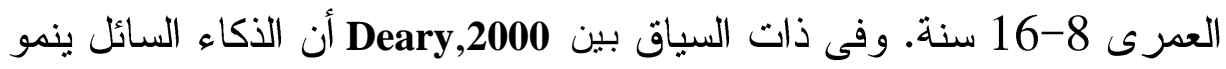

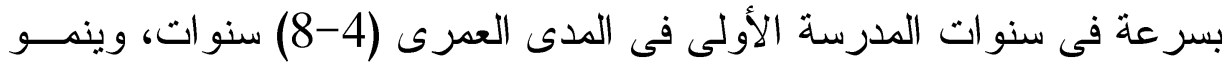


تدريجيا خلال المدى العمرى (10-14) سنة؛ ويصل الى أقصى نمو فى المدى العمرى (14-15) سنه ثم يتضاءل تدريجيا إيتذاء من عمر 22 سنة.

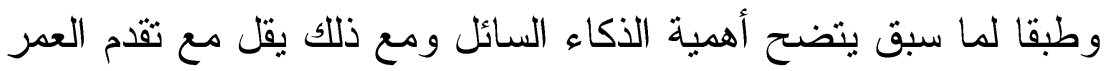

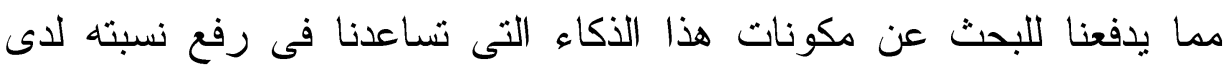
الأفر اد وخاصة الر اشدين. فالأكاء السائل يعكس قدرة الفرد على استدلال واستتاج العلاقات المجردة لحل

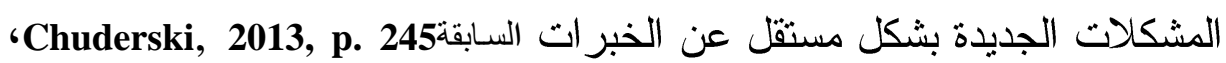

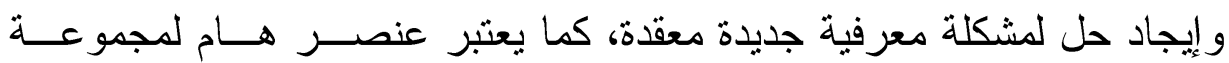

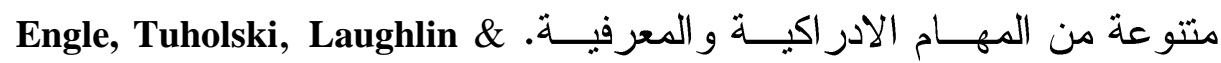
Conway, 1999; Gray \& Thompson, 2004, Alloway et al.,2012 ذلك منير حسن، 2005 بأن الذكاء السائل يعتبر المؤثر الفعال على المرونـــة

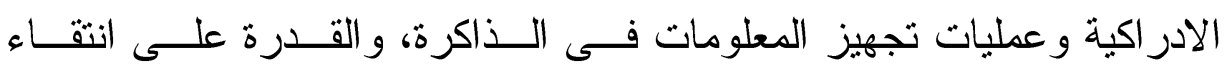
المعلومات المناسبة، و المرونة المعلوماتية فى مو اجهة المو اقف الجديدة. وقد أشار McGrew, 2006 عمليات عقلية تسيطر وتتحكم فى حل المشكلات المعقدة وغير المألوفة، و غالبا ما تشتمل هذه العمليات المعرفية على الاستتناج و الاستدلال، وتشكيل المفهوم Concept Formation Relations Generating and Testing Hypothesis Identifying المشكلاتProblem Solving، الاستقر اء Extrapolating، تحويـلـ المعلومــات Transforming Information McGrew, 2006, p.8

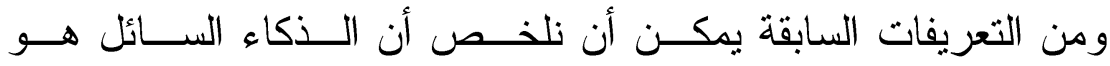

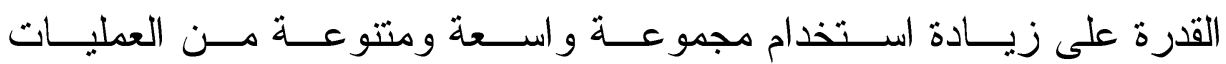
المعرفية الإبتدائية أو الأولية خلا لأل الأداء أو حل المشكلة الجديدة. 
وأثشار Alloway et al.,2012أن الذكاء السائل يقاس بو اســــة اختبــار ات حـل

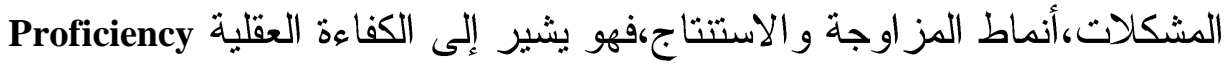

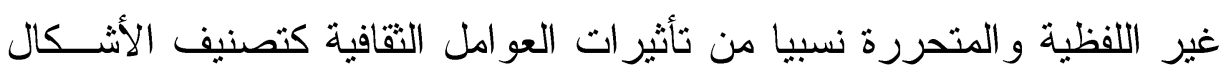

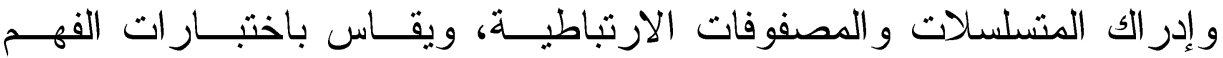

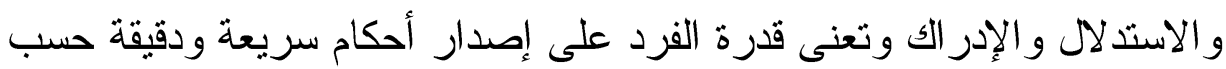

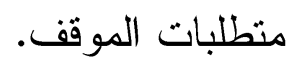

وفى هذا الاطار أثشارFabio \& Busoni, 2007 إلى أن اختبار المصفوفات

المتتابعة لر افن القياسى SMP وكذلك الاختبار المتقدم APM يعتبران من

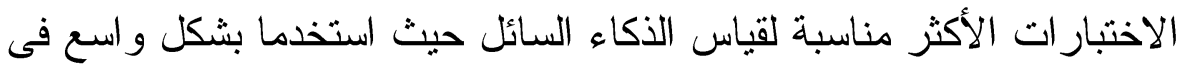

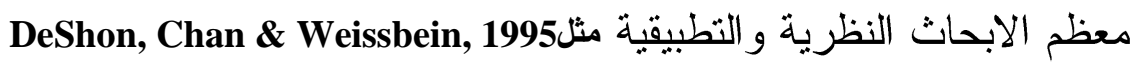
Alderton \& Larson, 1990 ;

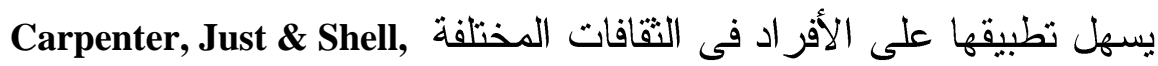
1990

و استهذفت العديد من الدر اسات التعرف على البناء العاملى للذكاء السائل مــــا

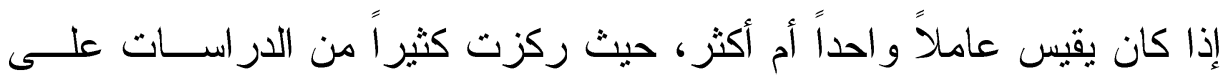
Van der Ven \& Hertzog \& Carter, اختبار رافن القباسى، مثل دراسة Ellis,2000,

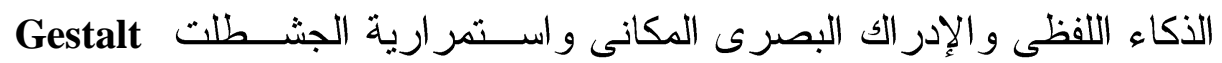
Continuation و الاستنتاج القياسى Analogical Reasoning على التو الى.

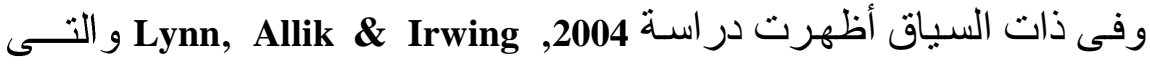
استخدمت التحليل العاملى الاستكشافى والتوكيــدى لاختبار SPM على عينـة من

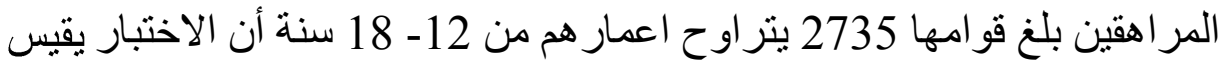

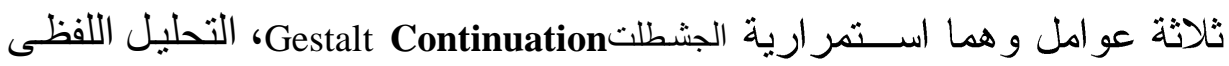
Visuospatial Ability Verbal-Analytic Reasoning 
مما تشير الى أن الذكاء السائل لا يمثل مكون عــاملى و احــد ولكـن متعــدد المكونات.

لم تقتصر الدراسات على SPM بل امتدت للتعرف على مكونات الذكاء السائل Dillon et al., باستخدام مصفوفات رافن المنقدم ومن هذه الدر اسات در اسة 1981

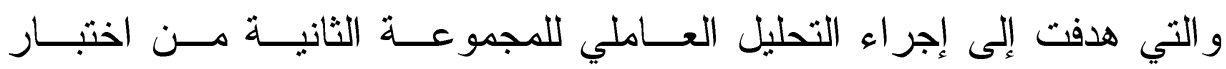

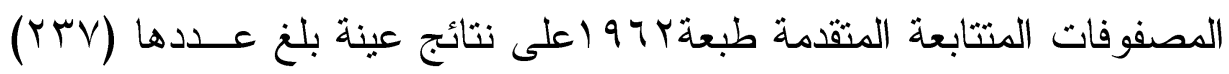
طالباً من طلاب مدرسة عليا ترأوحت أعمار هم بين(16- 18) سنة مع الأخذ

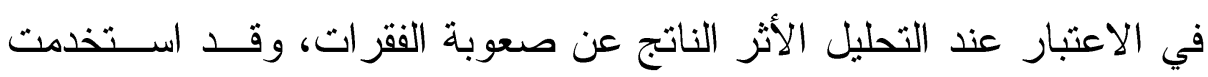
الدر اسة مقياس جتمان Guttman و الذي يقدر الحد الذي ينتج عنه مجموعــة مرتبة من الفقرات تزتياً تصاعدياً حسب مستوى الصعوبة، ومنطق هذا التحليل أنه كلما تم ترتيب الفقرات بشكل يمثل مقياس جتمان فهذا يعني أن الاختبــار

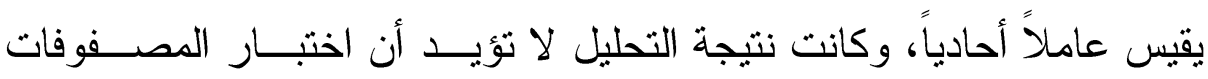

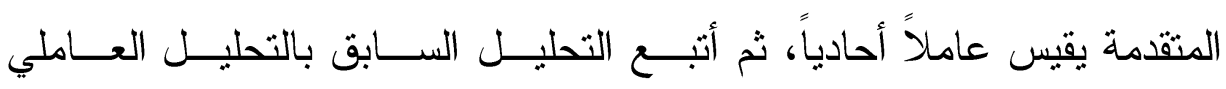

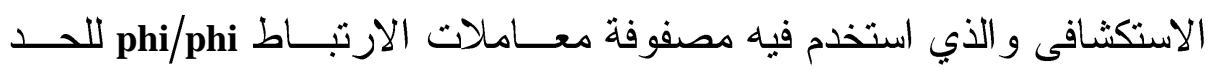
الاقصى بين الفقرات، وكانت نتيجة التحليل أن هنالك عاملين يقيسهما اختبار رافن المثقدم، الأول هو عامل الإضـــافة و الطــرح حـ The addition and/or the The ability to perceive subtraction of elements the progression of a pattern على مقاييس نقية نسبياً لتلك العو امل وذللك بتشكيل اختبارين فرعيين أحـدهما

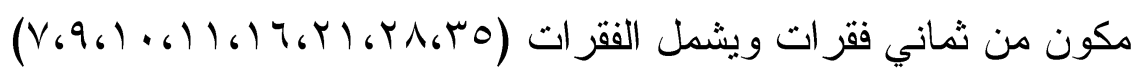
ويقيس العامل الأول، والآخر مكون من سبع فقرات ويشمل الفقرات

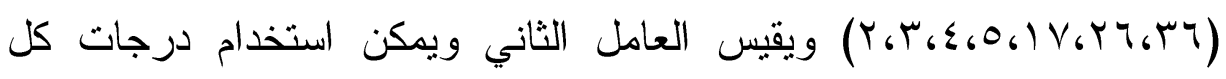
Dillon et al., 1981, اختبار فرعى على حده بدلاً من الدرجة الكلية على اختبار .p.1301 APM 
نتائج الدر اسة السابقة أدت إلى إجراء دراسة عاملية أخرى قام كل من

Dillon ودفت للتحقق من النتائج التي توصلت إليها Alderton\&larson, 1990 حيث قامت بتكرار إجر اءات الدراسة ولكن على عينتين كبيرتين منفصلتين تكونت من الذكور في السلاح الملاحي الأمريكي، وبلغ حجم العينة

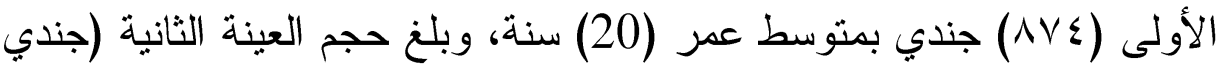

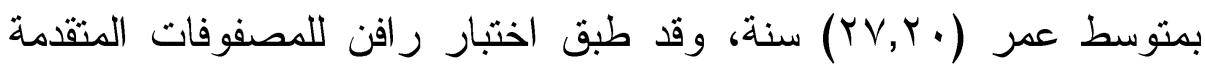

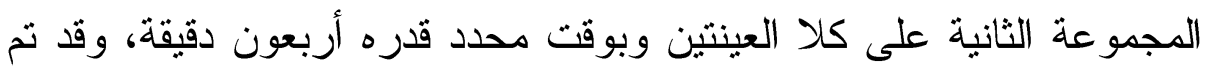
استبعاد الأفراد الذين تركوا فقرة أو أكثر دون إجابة أو لم يستطيعوا إكمال

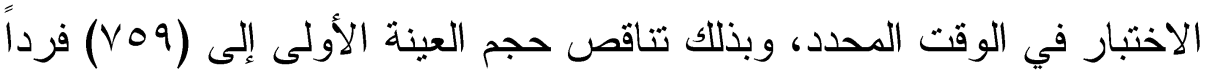

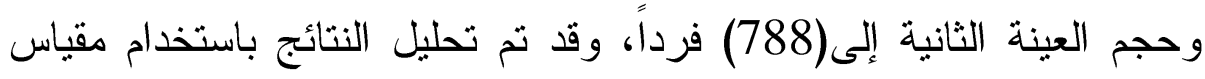
جتمان وكانت النتيجة أن الفقرات ليست ممثلة لمقياس جتمان بصورة مقنعة، ولئه ولكن الدرجة الكلية مؤشر جيد على أن الاختبار يقيس عاملاً عاماً، لذلك نم إيجاد الاتساق الداخلي للاختبار وذللك بإيجاد معامل الثبات باستخدام معادلة كودررنشاردسون • r و الذي بلغ (0.84) للعينة الأولى و (0.81) للعينة الثانية و هي قيم عالية وتؤكد بأن الفقرات متجانسة إلى حد كبير، ثم أتبع التحليل

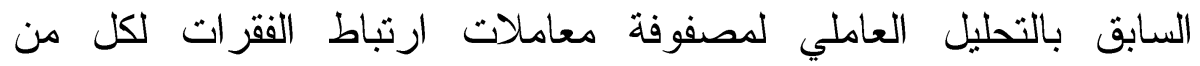
العينتين،كانت النتيجة التي توصلت إليها الدراسة تتعارض مع النتيجة التي

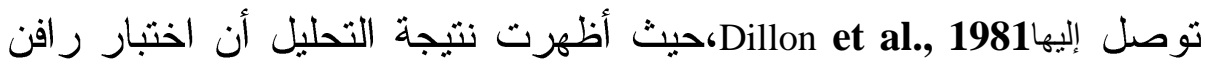
للمصفوفات المتتابعة المتقدم يقيس عاملاً عاماً أحادياً وليس عاملين.

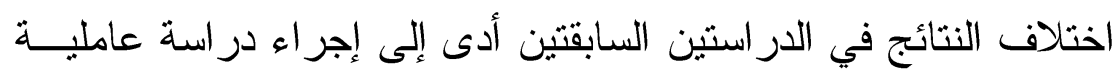

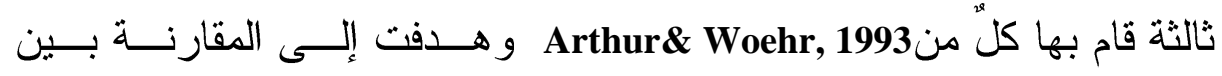

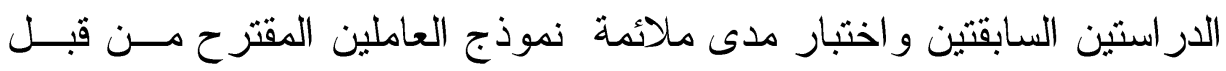
Dillon et al., 1981 Alderton\& larson, 1990 
نصفهم تقريباً من الإناث، متوسط اعمار هم 22.7 سنة وقد أكمل جميع أفراد العينة اختبار رافن المتقدم المجموعة الثانية وبدون تحديد وقت وعولجت الانت النتائج

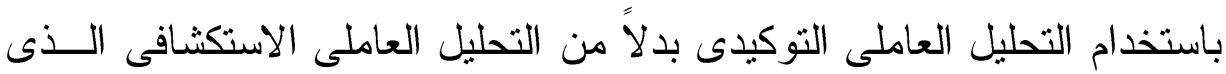

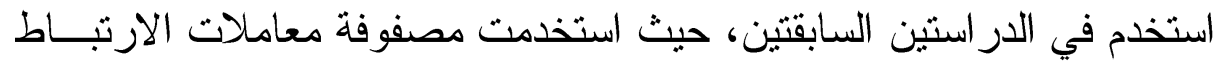
للفقرات و المحسوبة بو اسطة برنامج للحاسب الآلي كمدخل للنحليلات العاملية

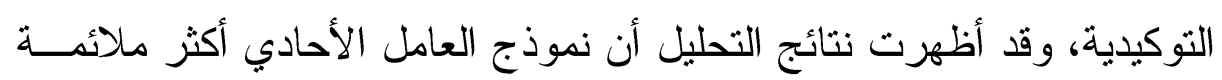
للبناء الداخلي لاختبار رافن المتقدم وهو ما يؤيده التطوير الأصلي و الاستخدام

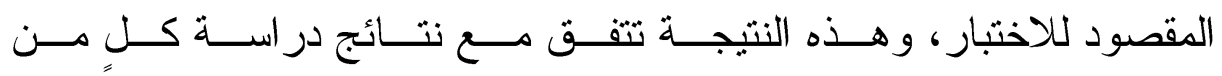
.Alderton\&larson,1990 كما أجريت دراسة عاملية رابعة سعت للتأكد من نتائج الدر اسات الثلاث

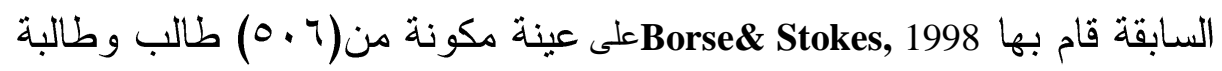
من طلاب السنة الأولى بجامعة تورنتو ، وقد استخدمت الدر اسة أساليب التحليل

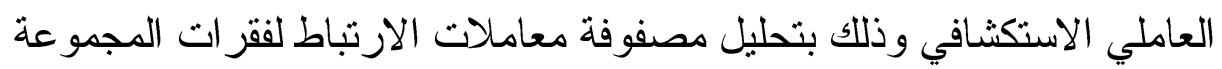
الثانية من اختبار رافن المتقدم وأظهرت النتائج أن العامل الأحادى أكثر ملائمة للاختبار من العاملين. كما تم استخدام أسلوب التحليل العاملي التوكيدي

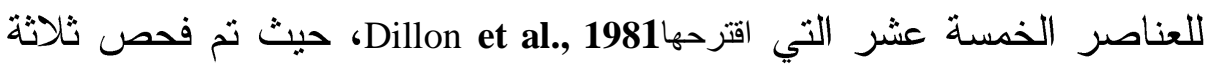
نماذج لتفسير البناء الداخلي لاختبار رافن، هي نموذج العامل الأحادي،

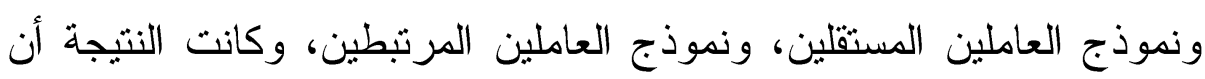

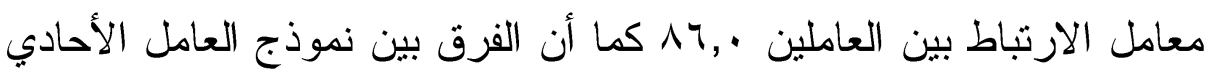

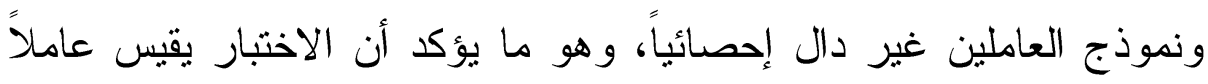
أحادياً وليس عاملين وبالتالي فإن نتائج التحليلات العاملية الاستكشافية

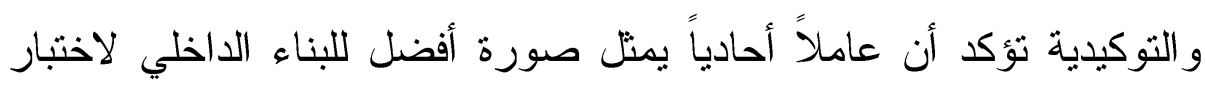
رافن المتقدم وهو ما يتفق مع نتائج كل من Arthur \& Woehr,1990, Alderton .\& larson,1993 
وفى ذات السياق توصل Woehr,1993 أن APM عامل واحد افضل نموذج معلاً ذلك بأن الارتباط بين عاملى الاختبار فى النموذج الثنائى كان مرتفعا

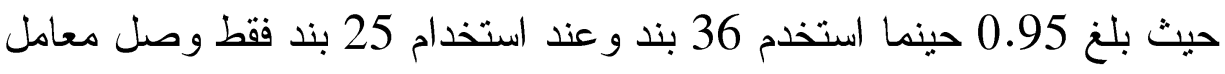
الارتباط بين العاملين(1)مما يشير إلى إنهما قد يكونا متمانلين بحيث يمثلا

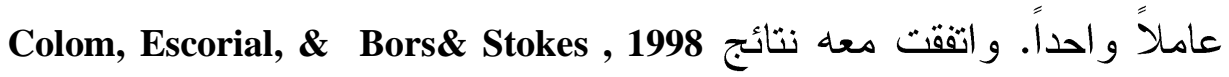
APM التى استخدمت التحليل العاملى الاستكثافى فى أن Rebollo, 2004

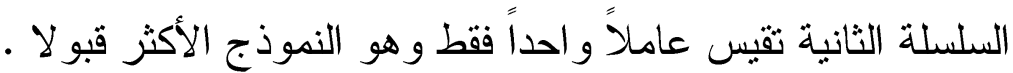
يتضح من نتائج التحليل العاملي في الدراسات السابقة لم تشر إلى

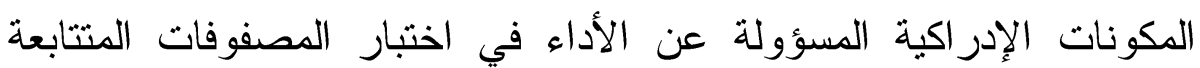
Carpenter, المتقدم،وللتعرف على تلك المكونات جرت عدة دراسات،حيث Just \& Shell,1990 بتحليل مصفوفة (APM) تحليلاً عاملياً وتوصل الى أنها تقيس خمسة قو اعد تفصيلية يمكن تصنيفها من حيث قو اعد معالجة المعلومات

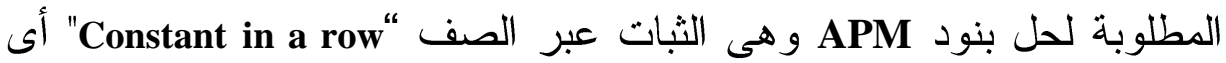
القيم تظل ثابتة داخل الصف و التغير ات تكون عبر الاعمدة و الزيادة الكمية عبر الاشكال المتجاورة Quantitative Pairwise Progressio"حيث يحدث التغيير المستمر في الحجم أو العدد أو الموضع بين الخلايا المجاورة عبر الصف الو احد وجمع/طرح شكلم:Figure Addition/Subtraction" حيث تتم إضافة أو طرح شكل فى العمود(جنبا إلى جنب أو متر اكبة)، للحصول على شكل ثالث مختلف.وقاعدة التوزيع الثلاثى للقيم Distribution of three Values" ، حيث توزيع لثلاث قيم مختلفة من الشكل يظهر في كل من الخلايا الثلاث على

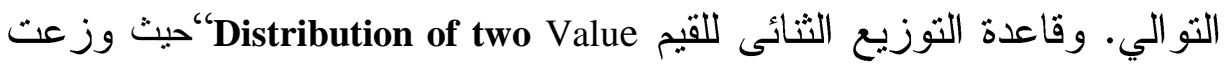
قيمتين من الثكل خلال الصف وقيمة الخلية الثالثة تكون فارغة، وقد أيدت الدراسة فكرة أن الفوارق في الأداء في اختبار المصفوفات المتتابعة المتقدم تتوقف على القدرة العامة، وقدرة الفرد على الترتيب، و السعة العقلية، و الذاكرة 
العاملة. وقد استبعدت الدراسة أهمية العامل البصري المكاني وبالتالي

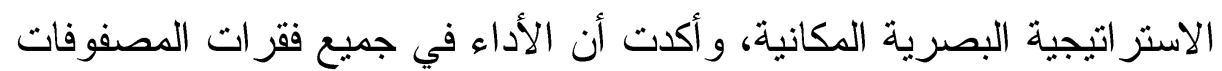
المتتابعة المتقدمة يتطلب مجموعة من قدرات الإدراك الأساسية المتجانسة الإديه

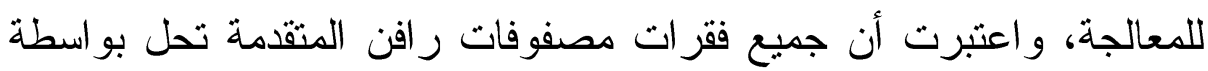

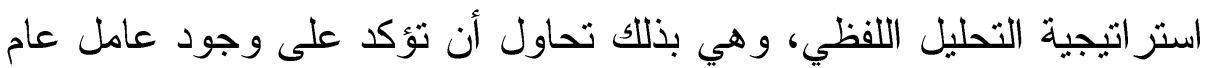
أحادي يفسر الأداء في اختبار المصفوفات المتتابعة المتقدم.

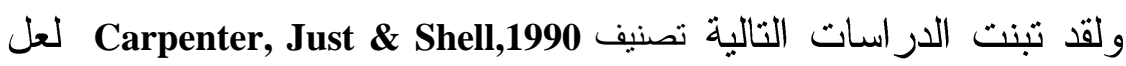

من أهمها دراسة DeShon Chan \& Weissbein, 1995 التى توصلت الى أن اختبار المصفوفات المتتابعة المتقدم لر افن يقيس عاملين حسب النمط السائد فى لهى معالجة حل البنود وهما التحليل اللفظى Verbal-Analytic وهي تلك التي يتم خلالها استخدام عمليات منطقية على الأشكال الموجودة في المسألة و الادر الك لهالئل البصرى-المكانى Visuospatial Abilities والتى تتعامل مع المسألة باستخدام البصر في الملاحظة مثل متابعة استمرارية الخطوط في المناطق الخالية، وتركيب الرموز المرئية فوق بعضها، كما أثنار الى أن جميع البنود التي لئي تتطلب القاعدة ثلاثية التوزيع لحلها حسب تصنيف Carpenter تقع تحت عامل التحليل اللفظى في حين أن البنود التى تحتاج قاعدة ثنائية التوزيع أو الجمع

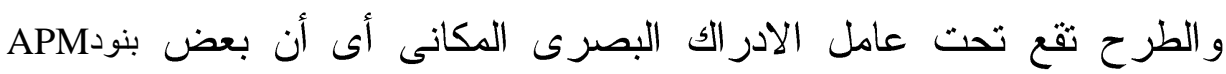
تعتمد على الجانب البصرى المكانى، في حين مجموعة اخرى تتطلب التحليل اللفظى DeShon Chan \& Weissbein ,1995, p.665 وقد دعمت هذه النتيجة ما توصل اليه Colom \& Garcia-Lopez, 2002 ان المصفوفات المتتابعة المتقدمة لر افن تقبس القدرة على الاستدلال والادر الك المكانى.

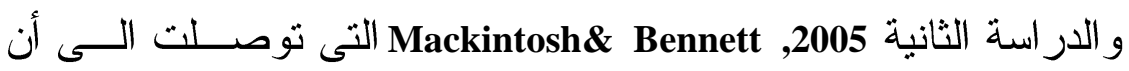

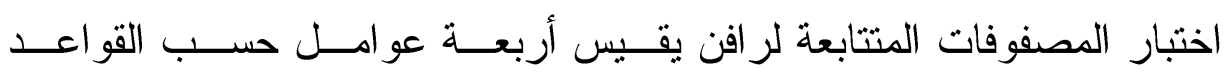

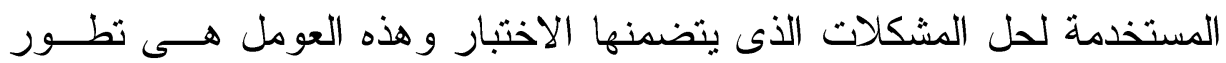




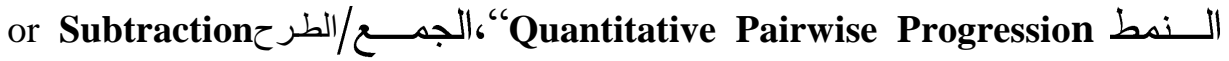
Figure Addition Distribution of three Values Distribution of two Values(D2) أن النموذج رباعى العو امل أفضل نموذج لاختبار APM حيث وجد أن مؤشرات المطابقة للنموذج الرباعى أفضل مقارنه بمؤشرات النموذج الاحادى. وقد أعاد التحليل العاملى لبيانات \&igneau \& Bors, 2005 Stokes, 1998 البند في الاختبار .فاشار إلى وجود عاملين فالبنود الموجودة فى أول الاختبار تعتبر عامل والبنود التى وضعت فى أخر الاختبار تعتبر عامل أخر وبالمثل صنف نموذج ثلاثى العوامل فى البداية و الوسط و النهاية أى صنفت العوامل على أساس موقعه فى الاختبار وأشاروا أن النموذج ذى عاملين هو الأكثر قبو لاً وكان معامل الارنباط بينهما 0.58 . يتضح من نتائج الار اسات ذات صلة بموضوع البحث الاختلاف فى عدد الابعاد التى يمكن أن يقيسها اختبار المصفوفات المتتابعة المتقدم لرافن حيث تراوحت بين بعد واحد إلى خمسة أبعاد ولعل هذا الاختلاف يمكن إرجاعه إلى Dillon et اختلاف حجم العينة التى تم إجراء التحليل عليها، فقى دراسة al.,1981 استخدم عينة صغيرة نسبيا 237 ومتجانسة نسبيا من طلاب المدارس الثانوية يتراوح اعمار هم من16-18 سنة، بينما در اسة Alderton \& Larson استخدما فيها عينتن كبيرتين نسبيا 874 و859، كما قد ترجع الى اختلاف Dillon et الاجر اءات حيث أن الدر اسات استخدمت إجراءات مختلفة حيث طبث al وقت، بينما حدد Alderton\& Larsonوقت الاجابة على الاختبار 40 دقيقة كحد اقصى علاوة على ذلك عمل على استبعاد المشاركين الذين لم يكموا الاختبار 
من التحليل وعليه يجب أن ننوه أن تحديد حد أقصى للوقت فى تطبيق اختبار APM مطلوب و هام لأنه يقيس الكفاءة الذهنية ولعل هذا الاختلاف في لئه العينات و الإجراءات تكون هى السبب فى اختلاف البناء العاملى فى كل هل

در اسة 2 . Raven et al., 1985, p.

وبالنظر الى اختبار المصفوفات المتتابعة المتقدم لرافن APM أنه يتكون

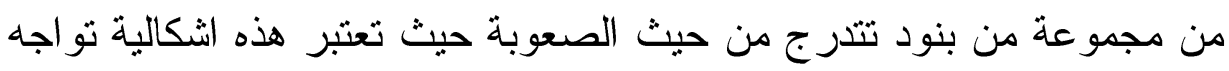

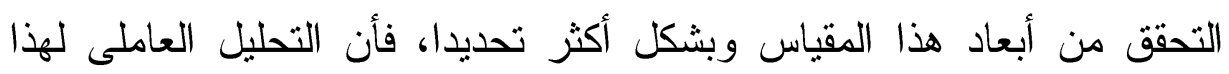

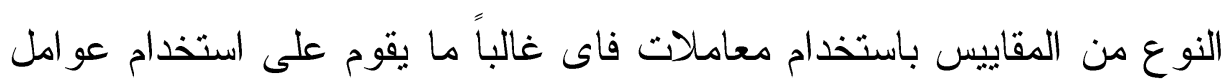

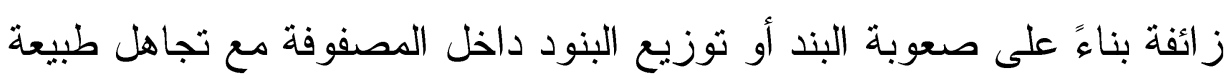
القدرة العقلية لحل هذه البنود و أسلوب معالجة المعلومات التى يتضمنه البند.

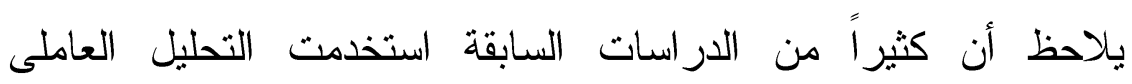
الاستكثافى فقط فى الكثف عن البناء العاملى للمصفوفة رافن ولتقديم مزيداً من الأدلة على أبعاد مصفوفة رافن المتقدم فقد تم تطبيق أسلوب التحليل

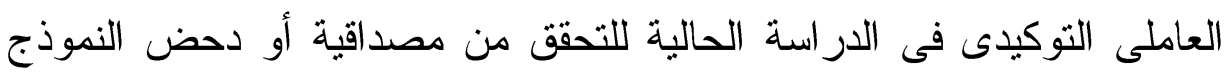

$$
\begin{aligned}
& \text { الناتج من التحليل العاملى الاستكشافى. } \\
& \text { فروض الاراسة : } \\
& \text { ينص فرض الدر اسة على أن : }
\end{aligned}
$$

الذكاء السائل لدى طلاب كلية التربية جامعة الفيوم قدرة متعددة العو امل.

$$
\text { إجراعات الاراسة: }
$$

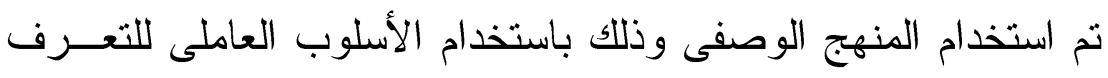
على البينة العاملية للذكاء السائل لدى طلاب كلية التزبية بجامعة الفيوم. عينة الار اسةة : 1 1عينة حساب الخصائص السيكومترية للاختبار : 
تكونت العينة من(90) طالب وطالبة(72\% اناث) من طلاب كلية

التزبية جامعة الفيوم، وذلك بهدف التحقق من الخصائص السيكومترية اختبار المصفوفات المتتابعة المتقدمة لر افن وتحديد زمن نطبيق الاختبار

$$
\begin{aligned}
& \text { فى ضوء متوسط أداء العينة. } \\
& \text { 2.عينة الدر اسة صوءة }
\end{aligned}
$$

تكونت عينة الدر اسة من 320 طالب وطالبة(86.8\% اناث) من طلاب كلية التربية جامعة الفيوم، وقد بلغ متوسط عدـــر العينــــ 20.56

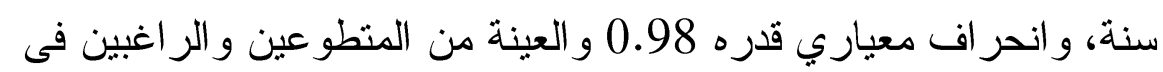

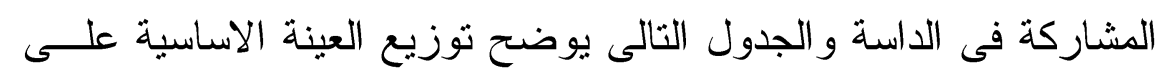
التخصصات المختلفة.

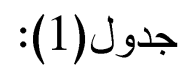

\begin{tabular}{|c|c|c|c|}
\hline \multirow[b]{2}{*}{ المجموع } & \multicolumn{2}{|c|}{ النوع } & \multirow[b]{2}{*}{ التخصص } \\
\hline & طالبة & طالب & \\
\hline 56 & 46 & 10 & اللغة العربية \\
\hline 76 & 67 & 9 & اللغة الإنجليزية \\
\hline 23 & 21 & 2 & اللغة الفرنسية \\
\hline 39 & 36 & 3 & مو اد اجتماعية \\
\hline 35 & 25 & 10 & التاريخ \\
\hline 33 & 31 & 2 & علم النفس \\
\hline 8 & 7 & 1 & الكيمياء \\
\hline 33 & 29 & 4 & الرياضيات \\
\hline 14 & 13 & 1 & البيولوجي \\
\hline 3 & 3 & - & الفيزياء" \\
\hline 320 & 278 & 42 & المجموع \\
\hline
\end{tabular}

توزيع أفر اد العينة الاساسية

أدوات البحث:

لاختبار المصفوفات المتتابعة المتقدم لي افن (1985)

Raven's Advanced Progressive Matrices 
وصف الاختبار

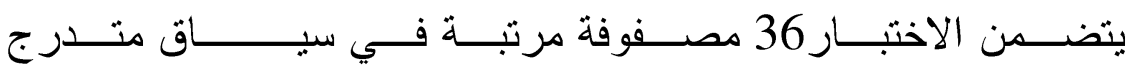

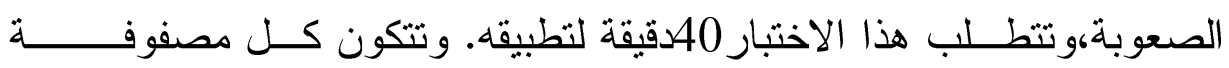

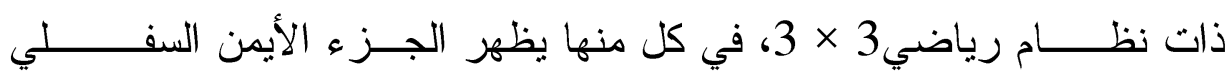

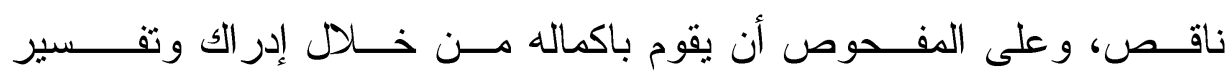

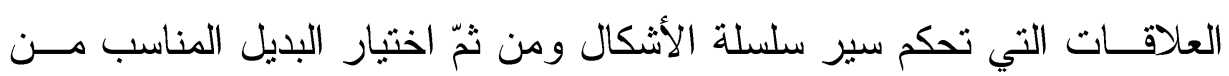

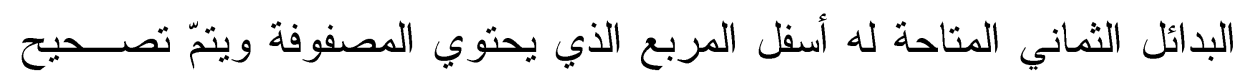

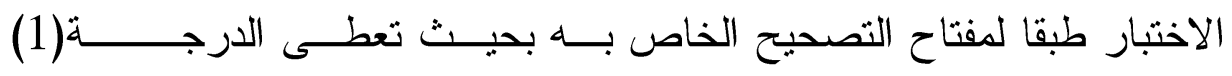
للاستجابة الصو اب، و الدرجة (صفر) للاستجابة الخطأ . الخصائص السيكومترية لاداة البحث 1. 1 - 1 الصدق الصدق التلازمى(صدق المحك)

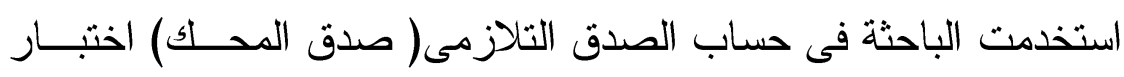

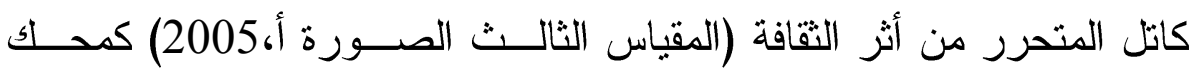

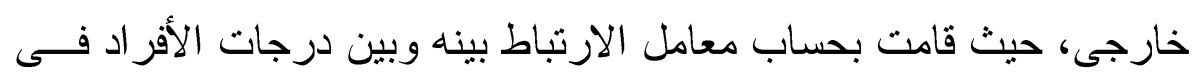

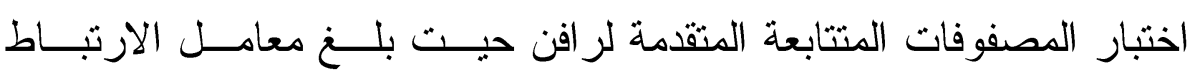

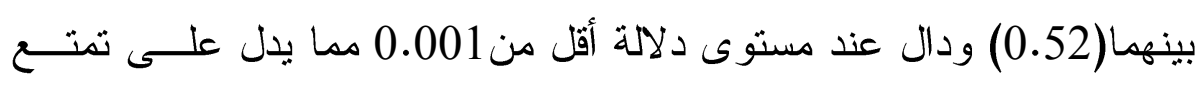

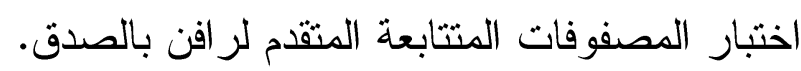
2. الثبات : وتم التحقق من ذلك باستخدام بعض مؤشر ات الثبات منها :

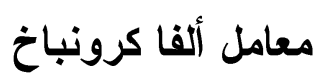

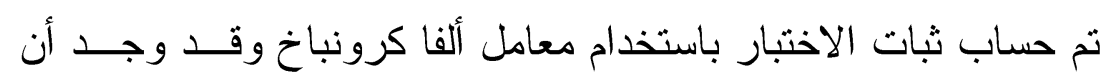

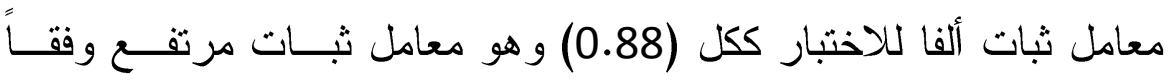
للمعايير القياسية. 3.الاتساق الاخلى للاختبار ، وتم التحقق من ذلك بحساب : 
معامل الارتباط بين المفردات و الدرجة الكلية للاختبار ، وتر اوحــت قـيم معاملات الارتباط بين (0.267 - 0.610) وكانت جميعها دالة إحصائياً عند مستوى (0.01) ( مست

\section{المعالجة الإحصائية :}

استخدمت الباحثة الأساليب الإحصائية التالية بواسطة الحزمة الإحصائية

فى العلوم الاجتماعية SPSS19، وبرنامج ليزرل LISREL8 1. التحليل العاملى الاستكثافى Exploratory Factor Analyses

2. التحليل العاملى التوكيدى Confirmatory Factor Analyses

$$
\text { نتائج البحث وتفسيرها: }
$$

لاختبار صحة الفرض الذى ينص على أن " الذكاء السائل لاى طلاب كليــة التربية جامعة الفيوم عبارة عن قدرة متعددة العوامل" تــم اســتخدام التحليـلـل العاملى الاستكشافى بطريقة المكونات الأساسية مع تدوير المحــاور بطريقــة الفاريماكس لدرجات الطلاب فى الذكاء السائل بالبرنامج الإحصائى SPSS19، وبعد ذلك استخدمت الباحثة التحليل العاملى التوكيـدى ببرنــامج LISREL8، وكانت النتائج كما يلى :

3.التحليل العاملى الاستكشافى Exploratory Factor Analyses

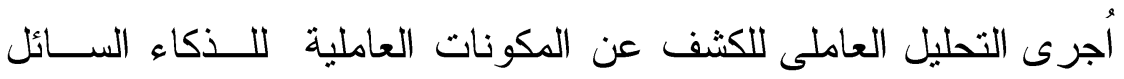
باختبار مصفوفة رافن المتقدم لقياس الذكاء السائل على عينة مكونة من(320) طالب وطالبة من كلية التربية جامعة الفيوم بطريقــة المكونــات الأساســية لهوتلنجPrincipal Component Analysis، وقد أسفر التحليل عن11 عاملاً. وقد رُوجعت معاملات الارتباط بمصفوفة الارتباطCorrelation Matrix لتأكد أن معظم معاملات الارتباط البينية تزيد عن 0.30 كمرحلة أولـى لصــلاحية 
التحليل، ووجد أن أكثر من ثلاث معاملات ارتباط تزيد قيمتهــا عـنـ0.30، علاوة على أنه رُوجعت القيم القطرية للمصفوفة الارتبــاط (Anti - Image)

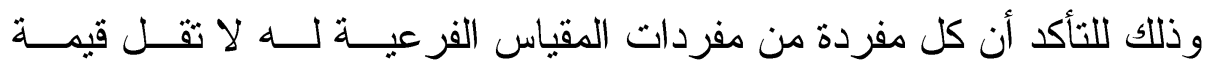
Measure of Sampling Adequacy (MSA) Kaiser-Meyer- 'KMO البنود(6،6، 3)، كما روجعت القيم الخاصة باختبار Olkin

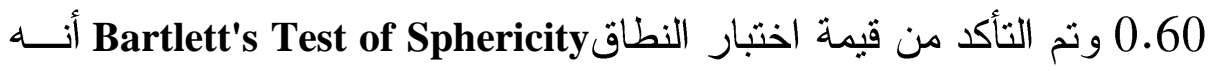
دال إحصائيا عند مستوى دلالة أقل من 00100 وروجعت كذلك قيم معاملات الثيوع وذلك للتأكد من أن كل مفردة تشبعت على عامل فقط و استخدم معيار

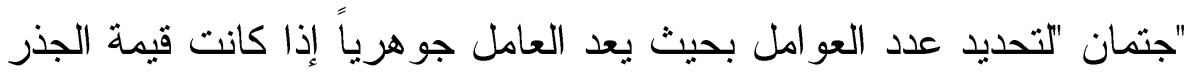

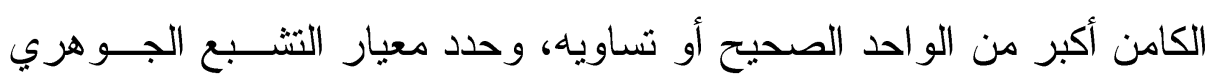

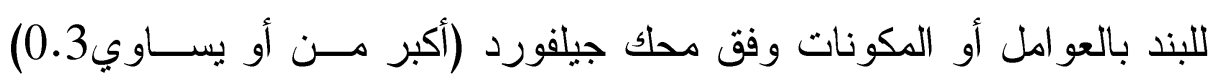

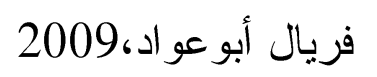

وللحصول على تكوين عاملى يمكن تفسيره تم تدوير المحسـاور تــدويراً

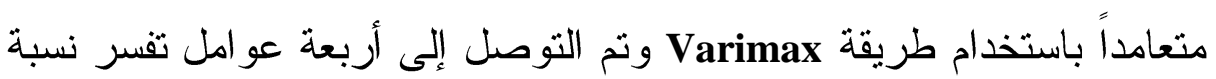

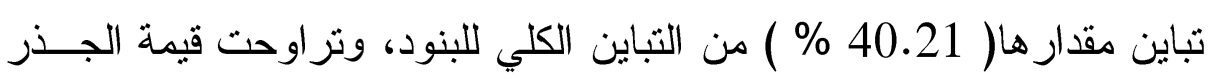

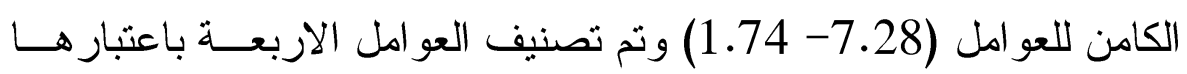

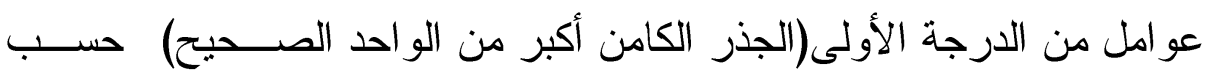
معيار جيتمان و الثكل التالى مخطط الجذور الكامنة للعو امل الاربعة.

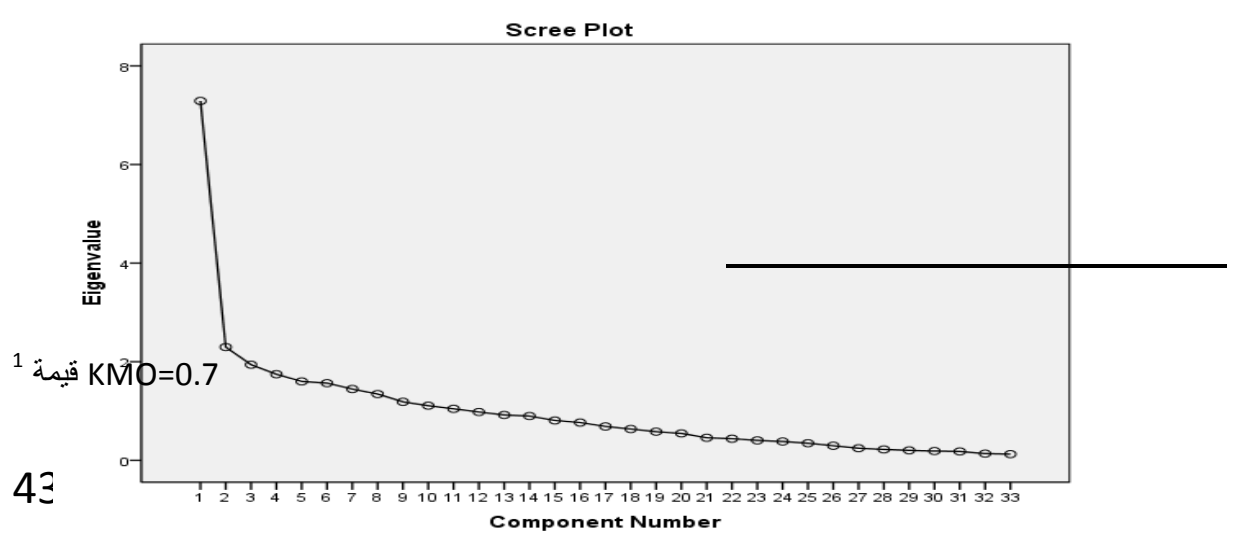


شكل(1) : مخطط الجذور الكامنة للعوامل الاربعة المكونة

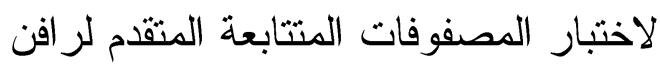

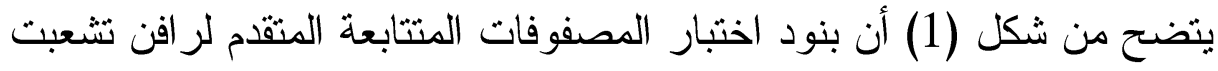

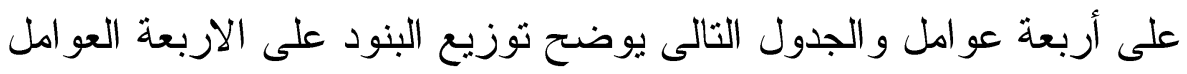
وتشبعتها.

جدول (2):نتائج التحليل العاملى الاستكثافى لاختبار المصفوفات المتتابعة

\begin{tabular}{|c|c|c|c|c|c|}
\hline \multirow{2}{*}{ الثعاملاع } & \multicolumn{4}{|c|}{ تثبعات العوامل } & \multirow[b]{2}{*}{ البنود } \\
\hline & الرابع & الثاثث & الثانى & الأول & \\
\hline 0.517 & & 0.381 & & & 1 \\
\hline 0.782 & & 0.708 & & & 2 \\
\hline 0.737 & & 0.587 & & & 4 \\
\hline 0.720 & & 0.374 & 0.467 & & 7 \\
\hline 0.586 & & & 0.434 & & 8 \\
\hline 0.646 & & & 0.418 & & 9 \\
\hline 0.730 & & 0.587 & 0.348 & & 10 \\
\hline 0.721 & & & 0.611 & & 11 \\
\hline 0.731 & & 0.327 & 0.357 & & 12 \\
\hline 0.589 & & 0.352 & & & 13 \\
\hline 0.737 & & & 0.348 & 0.413 & 14 \\
\hline 0.681 & & & 0.676 & & 15 \\
\hline 0.674 & & & & 0.407 & 16 \\
\hline 0.789 & & & & 0.303 & 17 \\
\hline 0.670 & & & 0.308 & 0.496 & 18 \\
\hline 0.770 & & & 0.604 & & 19 \\
\hline 0.560 & & & & 0.519 & 20 \\
\hline 0.683 & & 0.592 & & & 21 \\
\hline 0.608 & & & & 0.601 & 22 \\
\hline 0.663 & & & & 0.454 & 23 \\
\hline 0.656 & & 0.418 & & 0.427 & 24 \\
\hline 0.755 & 0.664 & & & & 25 \\
\hline 0.631 & & & & 0.668 & 26 \\
\hline
\end{tabular}




\begin{tabular}{|c|c|c|c|c|c|c|}
\hline 0.647 & 0.373 & 0.380 & & 0.369 & & 27 \\
\hline 0.730 & 0.662 & & 0.377 & & & 28 \\
\hline 0.648 & 0.661 & & & & & 29 \\
\hline 0.689 & 0.323 & & & 0.664 & & 30 \\
\hline 0.718 & & & & 0.705 & & 31 \\
\hline 0.693 & & & 0.354 & 0.399 & & 32 \\
\hline 0.642 & 0.490 & & & 0.337 & & 33 \\
\hline 0.663 & 0.362 & & & 0.510 & & 34 \\
\hline 0.714 & & & & 0.652 & & 35 \\
\hline \multirow[t]{3}{*}{0.663} & 0.414 & & 0.328 & 0.436 & & 36 \\
\hline & $\begin{array}{l}1.74 \\
0 / 520\end{array}$ & $\begin{array}{l}1.93 \\
0 / 587\end{array}$ & 2.29 & 7.28 & ن الجذر الكامن & \\
\hline & \multicolumn{4}{|c|}{$\% 40.21$} & نسبة التباين الكلية & \\
\hline
\end{tabular}

يتضح من جدول(2) أن الذكاء السائل المقاس باختبار المصفوفات

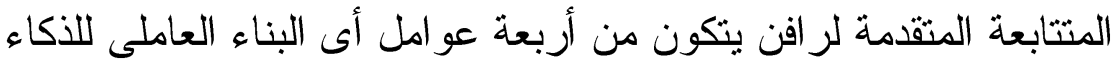

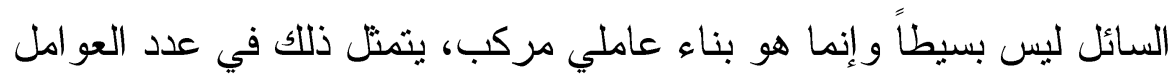

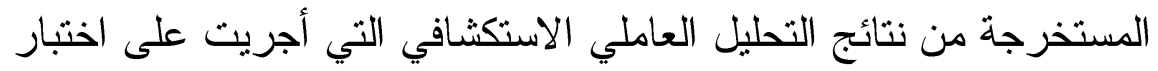

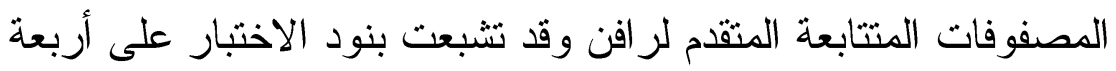

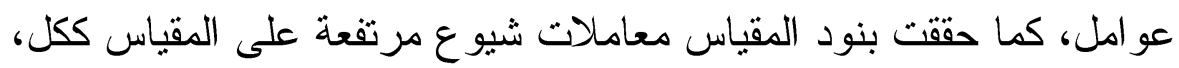

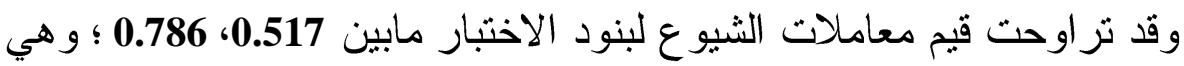

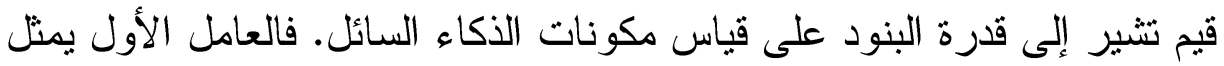
القدرة على الاستتناج ويعنى قدرة الفرد على التفكير واستخلاص النتائج من الشروط العامة أو الخاصة المخصصة لحل المشكلة، ويفسر هذا العامل نسبة ولية من التباين قدرها 22.08 \% و، وقد تشبع عليه 15 بند(31- 26 - 30 -35-

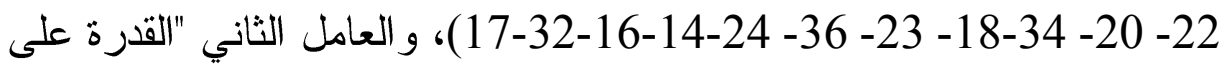
التفكير الحثى أو الاستقرائى ويعنى القدرة على الجمع بين أجزاء منفصلة من

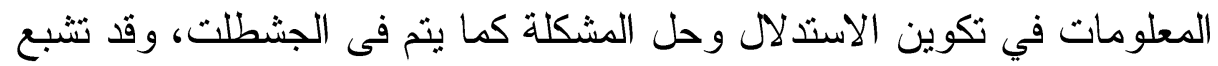
عليه 7 بنود(15-11-19-7-8-9-12)، ويفسر نسبة من التباين قدرها 6.96 \%، و العامل الثالث " الاستدلال الكمى" ويعنى القدرة على التفكير الذى يتضمن العلاقات الرياضية من جمع وطرح الاشكال وقد تشبع عليه 7 بنود(1-2-10- 
27-21-4-13)، ويفسر نسبة من التباين قدرها 5.87 \% و والعامل الر ابع "البصرى -المكانى" ويعنى قدرة الفرد على التدوير الذهنى للاشكال فى مكانها وقد تشبع عليه 4 بنود(25-28-29-33)، ويفسر نسبة من التباين قدرها

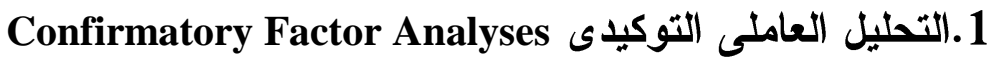
وللتحقق من صدق البنية الكامنة لاختبار المصفوفات المتتابعة المتقدم لر افن فقد استخدم التحليل العاملي التوكيدي باستخدام برنامج LISREL8، من من مديه خلال دراسة مدى ملاءمة البيانات التي جمعت للنموذج المستتبط من نتائج التحليل العاملي الاستكثافي الذى افترض أن الذكاء السائل يتكون من أربعة أنسات مكونات. وكما هو مبين في النموذج شكل (2) الذي تم الحصول عليه من لاهن خلال إجراءات التحليل العاملي التوكيدي . 


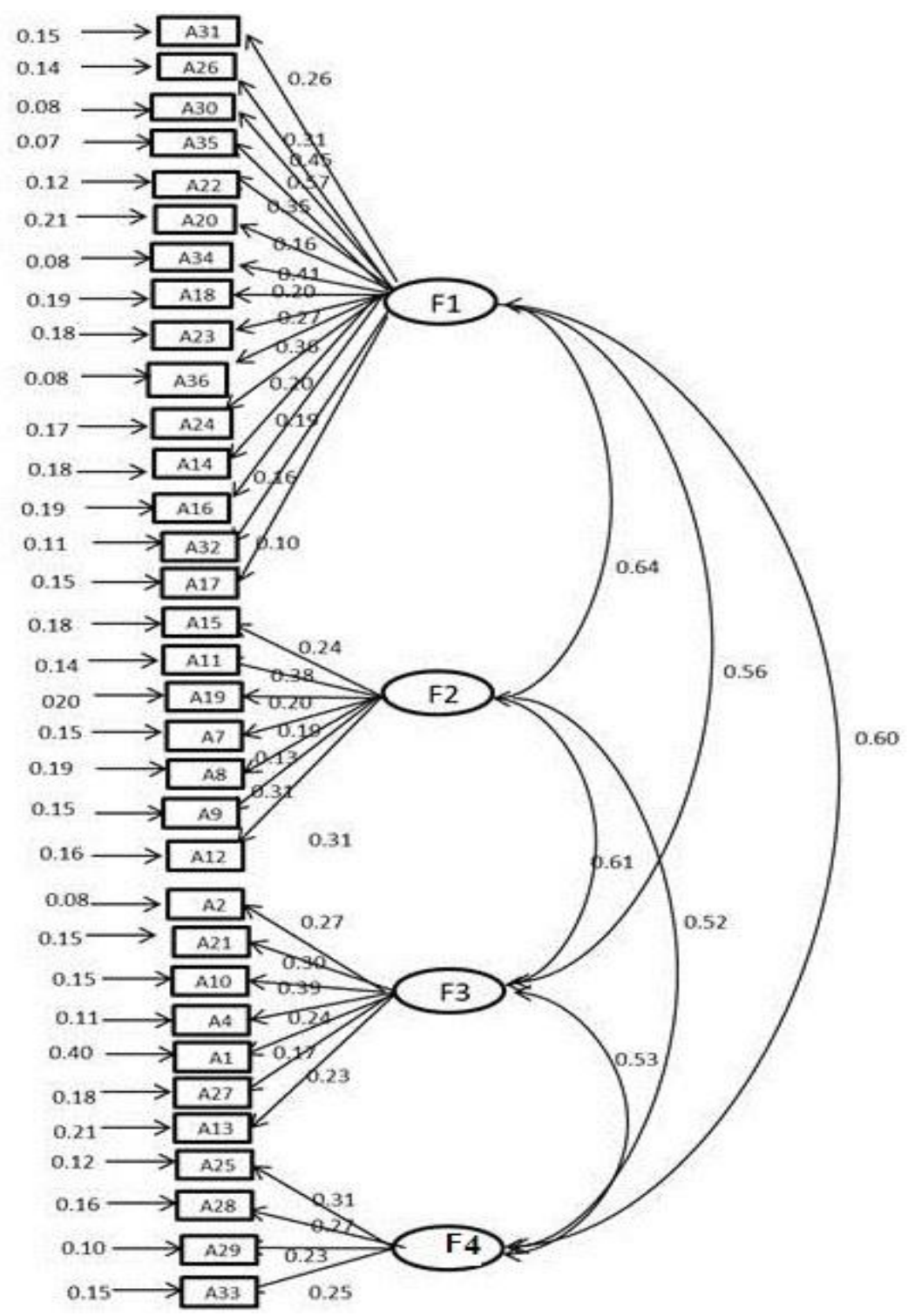

شكل(2) :البنية الكامنة لاختبار المصفوفات المتتابعه لمثقدم لر افن ويبين الجدول(3)مؤشرات مطابقة النموذج لبيانات اختبار المصفوفات المتثابعة المتقدم لر افن التي طبقت على عينة التقنين. جدول (3):مؤشرات مطابقة البيانات لنموذج البنية الكامنة للذكاء

$$
\text { السائل (320 (32) }
$$


البنية العاملية للاكاء السائل لاى طلاب كلية التربية جامعة الفيوم د. عائشة على رف عطية

\begin{tabular}{|c|c|c|c|c|c|c|c|}
\hline (\%90)RMSEA & CAIC & GFI & NNFI(TLI) & SRMR & df & $x^{2}$ & النموذج \\
\hline 0.065 & 2996 & 0.89 & 0.79 & 0.091 & 496 & 962 & واحل \\
\hline 0.063 & 3592 & 0.90 & 0.82 & 0.087 & 493 & 956 & عاملان \\
\hline 0.043 & 2708 & 0.91 & 0.90 & 0.08 & 492 & 954 & تُلاثله \\
\hline 0.034 & 2615 & 0.95 & 0.93 & 0.07 & 489 & 948 & عوامل \\
\hline
\end{tabular}

بمقارنة مؤشرات المطابقة لكل نموذج فى الجدول السابق نجد ان افضل نموذج هو النموذج المكون من اربعة عوامل حيث نجد أن قيمة غير دالة إحصائيا عند أي مستوى من مستويات الدلالة الإحصائية، وأن قيم مؤشر جودة المطابقة (1) Goodness-of-Fit Index GFI تقترب قيمتهما من من (1) مما بدل مطابقة النموذج للبيانات Diamantopoulos \& Siguaw, 2000 وقيمة هودة المؤشر الجذر التربيعي لمتوسط خطأ الاقتراب Root Mean Square Error (RMSEA) of Approximation (0.06-0.06) بل يقترب من الصفر مما يدل على مطابقة النموذج للبيانات Browne, 2006 مصطفى حفيضة،2013. كما أن مؤشرات المطابقة المتز ايدة المعيارى NNFI) Non Normed Fit Index (تقترب قيمتها من(1) حيث قيمتها اكبر من Byrne, 1998) ، كما أن قيمة مؤشر جذر منوسط (SRMR) Standardized Root Mean Square مربعات البو اقي المعيارية Residual

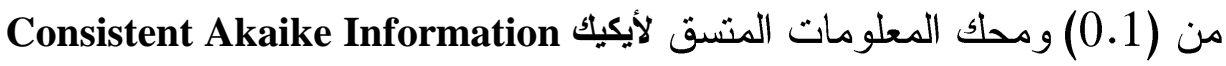
(CAIC) Criterion الاخرى، بما يدل على جودة مطابقة بيانات النموذج رباعى العوامل للنموذج لهون

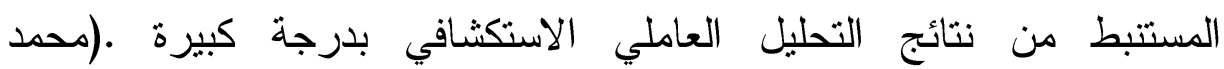

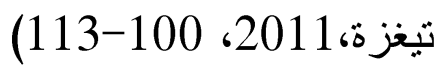




\section{مناقشة النتائج}

أظهرت نتائج الدراسة الحالية للتحليل العاملى الاستكشافى أن الذكاء

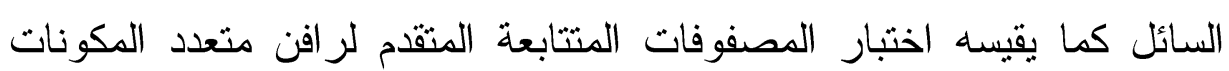

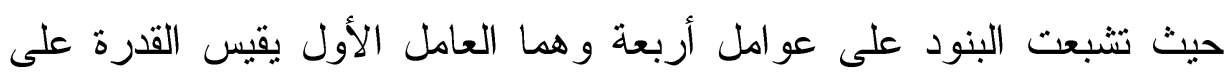

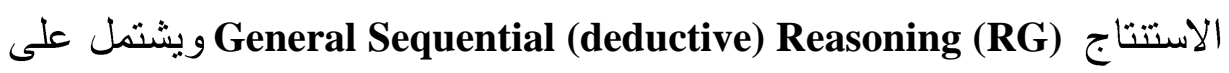
أكبر عدد من البنود وهذا هو الهدف الرئيسى من الاختبار ويعنى قدرة الفرد

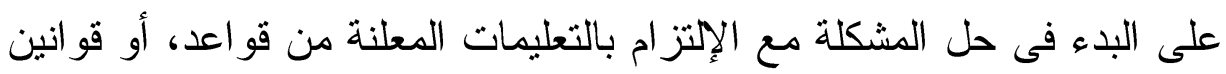
وشروط، والاخول فى خطوة واحدة أو أكثر تؤدى إلى حلى الئى الثكلة فالعمليات

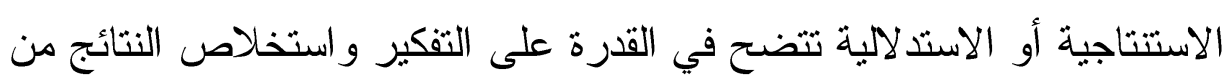

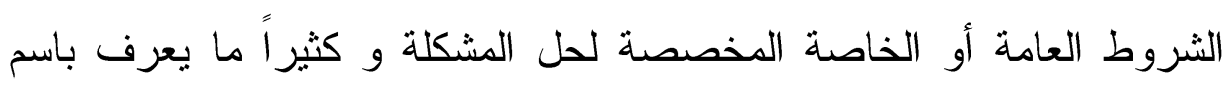

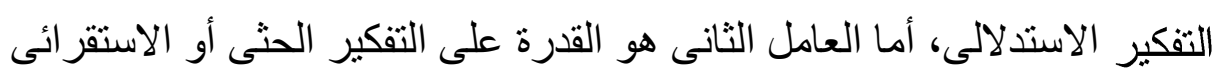
Induction

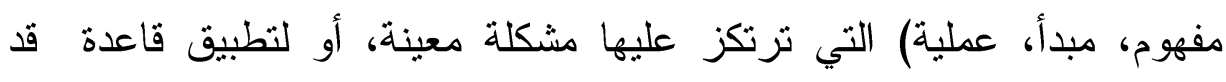
تعلمت سابقا لحل هذه المشكلة فالتفكير من خلال حالات محددة أو ملاحظات

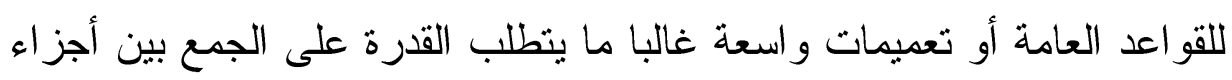

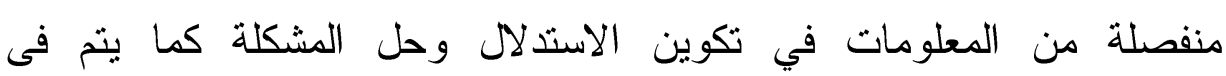
الجشطلت ويتفق كل منLynn, Allik \& Irwing ,2004, .Dillon et al., 1981. مع هذه النتيجة بوجود مكون التفكير الاستقر ائى كأحد مكونات الذكاء السائل .

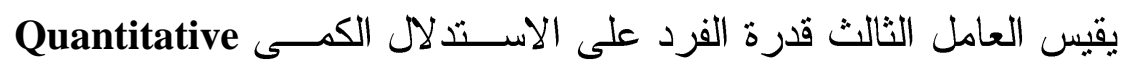
ويعنى القدرة على التفكير الذى يتضمن العلاقات الرياضية

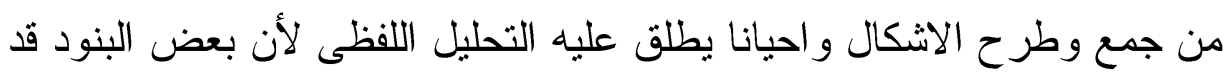
تطلب من الأفراد القيام بعملتى الجمع و الطرح للاشكال داخل المصفوفة لفظياً

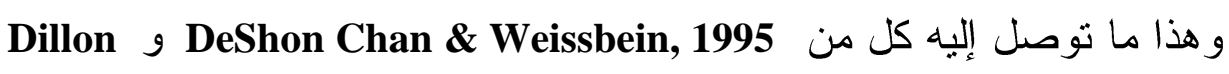
Visuospatial و العامل الر ابــع الادر الك البصــرى المكــــــ et al., 1981 443 
Ability

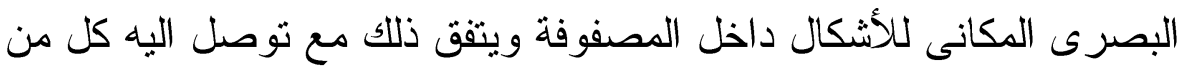
. Lynn, Allik \& Irwing ,2004; DeShon et al., 1995.

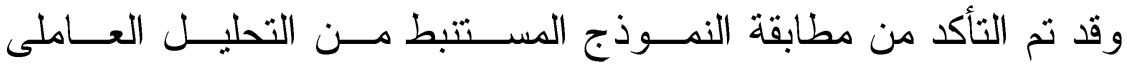

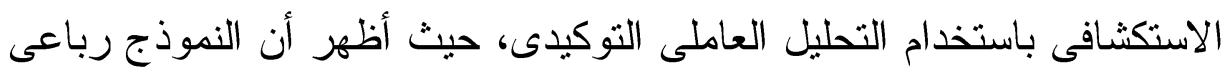

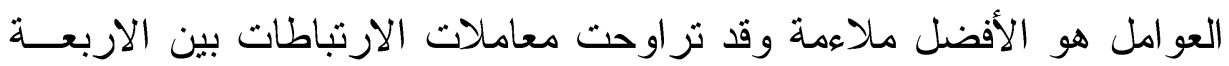

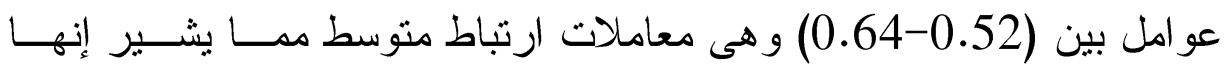

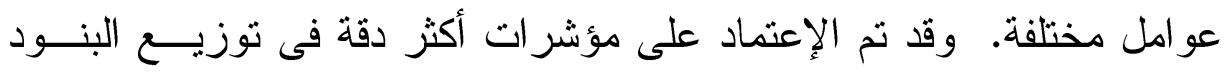

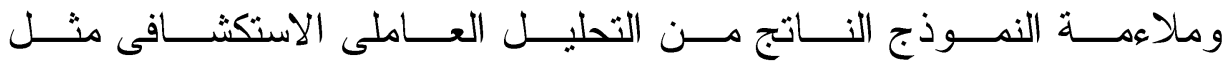
(SRMR,NNFI(TLI) GFI, CAIC, RMSEA, Vigneau \& Bors, 2005; Dillon معاملات الصعوبة و السهولة كما فى در اسلة et al.,1981 التى وزعت البنود على العو امل بناءٌ على صعوبة البند. وتتفق نتيجة البحث الحالى مع وجهة النظر القائلة أن الذكاء السائل

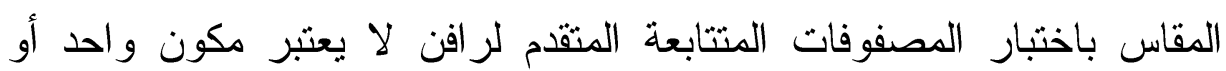

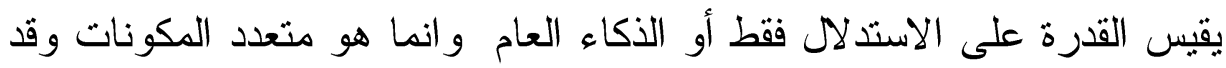

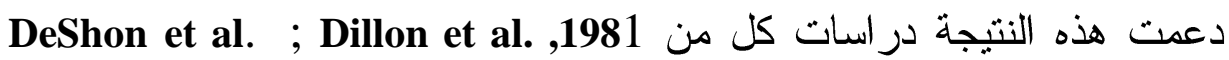
1995, التى أشارت إلى أن الذكاء السائل عبارة عن مكونين وهما القدرة على على ألى

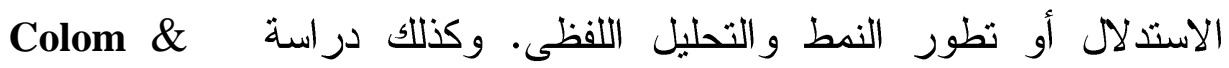
Garcia-Lopez, 2002 و الادر الك البصرى المكانى وكذلك در اسة Lim, التى اكدت نفس النتيجة، 1994 ودراسة Van der Ven \& Ellis,2000 التى اظهرت أن الذكاء السائل مكونين هما الذكاء اللفظى والادر اك البصرى المكانى وليس مكون و احد ودعمت هذه النتيجة ما توصل اليه كل من 2004, Lynn, Allik \& Irwing أن الذكاء السائل ثلاث مكونات وهما التحليل اللفظى و استمرارية الجشطلت و الادر اكل

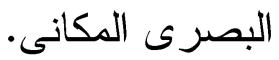


وفى ذات السياق تتفق ايضا نتيجة البحث الحالى ايضا مع ما توصل اليه Mackintosh \& Bennett's, 2005 العو امل والنموذج رباعى العوامل يعتبر أفضل النماذج المفسرة للذكاء السائل باستخدام مصفوفة رافن المتقدم.

وتدعم نتيجة البحث الحالى ما توصل اليه McGrew,2006 على مأنى أن مأن الذكاء السائل هو قدرة الفرد على حل المشكلات الجديدة و المبتكرة باستخدام

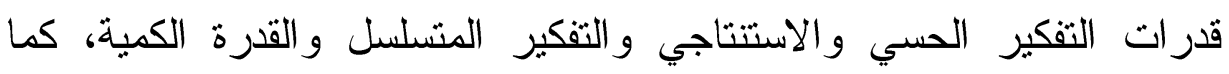
يتضمن القدرات التي تستخدم الاستدلال وتحديد وتصنيف العلاقات وتغيير

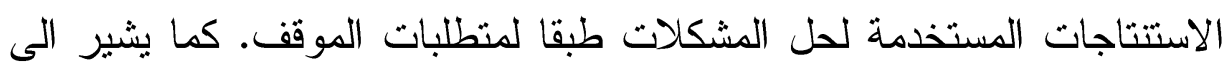
أن الذكاء السائل قرة عامة تتكون من عدد من القرات الفرعية، تتضمن

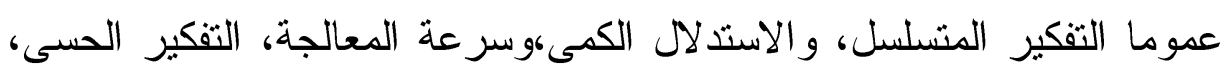
و التدوير الذهنى والقدرة على الاستتناج أى إنه متعدد المكونات وليس مكون ولئل

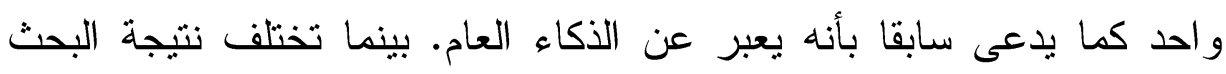

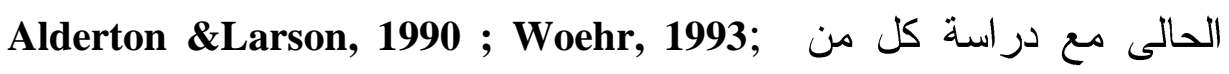
Colom ,Rebollo\& Escorial, 2004; Bors\& Stokes, 1998 تزعم بأن الذكاء السائل مكون واحد يمثل القدرة العقلية العامة. 


$$
\text { من نتائج الدراسة توصيات ومقترحات الدراسة : }
$$

1. تصميم برامج تدريبية لتتمية مهار ات الطلاب المرتبطة بمكونات الذكاء

السائل.

2. التعرف على المكونات العاملية للذكاء السائل لدى شرائح عمرية

مختلفة.

3. إجر اء دراسات عبر تقافية لتحديد مكونات الذكاء السائل وما اذا كانت

$$
\text { مختلفة باختلاف الثقافة. }
$$




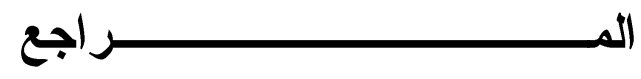

\section{أولاً : المراجي العربية}

1.محمد تيغزة (2011). اختبار صحة البنية العاملية للمنغير ات الكامنة فـي

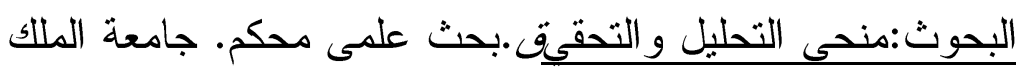

سعود.

2.مصطفى حفيضة سليمان(2013). فعالية استخدام استر اتيجية التعلم الـــاتى

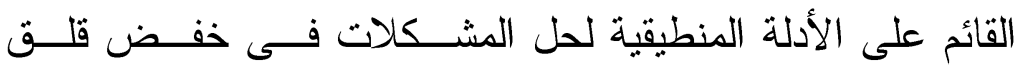

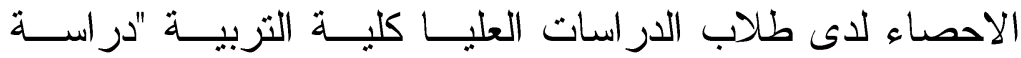

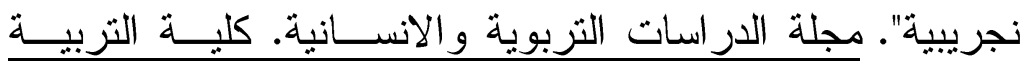

جامعة دمنهور، 5(4)، الجزء الأول.

3.منير حسن جمال(2005). اضطر ابات وظائف المكونات الشعورية للأكرة

العاملة كدالة لقصور الأداء الوظيفى للعمليات الشعورية وعلاقتشها

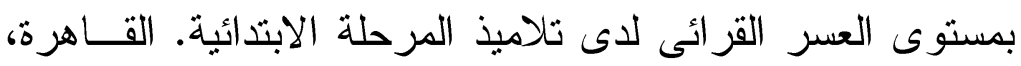

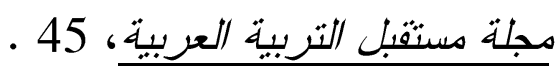

4.فريال أبو عواد(2009). البنية العاملية لمقياس الدافعية الاكاديميـة (AMS)

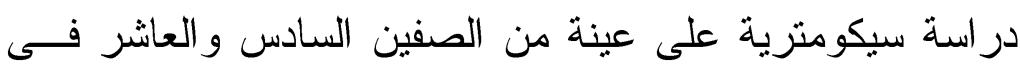

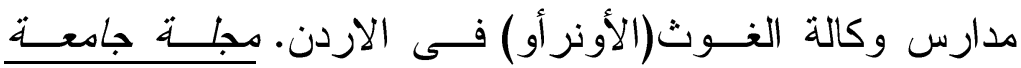

\section{دمشق، 25 (3).}

ثانباً : المراجي الاجنيية

1.Alderton, D. L., \& Larson, G. E. (1990). Dimensionality of Raven's Advance Progressive Matrices. Educational and Psychological Measurement, 50, 887-900.

2.Alloway, T. P., \& Alloway, R. G. (2012). Working memory: The connected intelligence. New York: Psychology Press.

3.Arthur, W. \& Woehr, D. J. (1993). A confirmatory factor analytic study examining the dimensionality of the Raven's Advanced Progressive Matrices. Educational and Psychological Measurement, 53, 471-497. 
4.Brown, T. A. (2006). Confirmatory Factor Analysis for Applied Research. New York: The Guilford Press.

5.Byrne, B.M. (1998). Structural Equation Modeling with LISREL, PRELIS and SIMPLIS : Basic Concepts, Applications, and Programming. New Jersey: Lawrence Erlbaum Associates, Publishers.

6.Bors, D. A., \& Stokes, T. L. (1998). Raven's Advanced Progressive Matrices: Norms for first-year university students and the development of a short form. Educational and Psychological Measurement, 58, 382-398.

7.Carpenter, P. A., Just, M. A., \& Shell, P. (1990). What one intelligence test measures: A theoretical account of the processing in the Raven Progressive Matrices test. Psychological Review, 97, 404-431.

8.Chuderski, A. (2013). When are fluid intelligence and working memory isomorphic and when are they not?. Intelligence, 41, 244-262.

9.Colom, R., \& Garcia-Lopez, O. (2002). Sex differences in fluid intelligence among high school graduates. Personality and Individual Differences, 32, 445-451.

10.Colom, R., Escorial, S., \& Rebollo, I. (2004). Sex differences on the Progressive Matrices are influenced by sex differences on spatial ability. Personality and Individual Differences, 37, 1289-1293

11.Colom, R., Román., F., Abad, F., Chun Shih, P., Privado, J., Froufe, M., Escorial, S., Martínez, K., Burgaleta, M., Quiroga, M., Karama, S., Haier, R.., Thompson, P. \& Jaeggi, S.(2013). Adaptive n-back training does not improve fluid intelligence at the construct level: Gains on individual tests suggest that training may enhance visuospatial processing. Intelligence, 41, 712-727.

12.Deary, I. J. (2000). Looking down on human intelligence: From psychometrics to the brain. New York: Oxford University Press.

13.DeShon, R. P., Chan, D., \& Weissbein, D. A. (1995). Verbal overshadowing effects on Raven's Advanced Progressive Matrices: Evidence for multidimensional performance determinants. Intelligence, 21, 135-155.

14.Diamantopoulos, A. \& Siguaw, J. (2000). Introducing LISREL. Thousand Oaks, CA: Sage Publications. 
15.Dillon, R. F., Pohlmann, J. T., \& Lohman, D. F. (1981). A factor analysis of Raven's Advanced Progressive Matrices. Educational and Psychological Measurement, 41, 12951302.

16.Duncan, J. (2003). Intelligence tests predict brian response to demanding task events. Nature Neuroscience, 6, 939-944.

17.Engle, R.W, Tuholski, S.W, Laughlin, J.E, Conway. (1999) Working memory, short-term memory, and general fluid intelligence:Alatent variable approach. $J$ Exp Psychol General, 128, 309-331.

18.Feldman, R.(1996). Understanding Psychology, (Fourth Edition) McGraw Hill.

19.Fabio, A.D., \& Busoni, L. (2007).Fluid intelligence,Personality traits and scholastic success: Empirical evidence in a sample of Italian high school students. Personality and Individual Differences, 43, 2095-2104.

20.Gottfredson, L. S. (1997). Why g matters: The complexity of everyday life. Intelligence, 24,79-132.

21.Gray , R., Thompson.P,M. (2004) Neurobiology of intelligence: Science and ethics. Nat Rev Neurosci, 5, 471-482.

22.Hertzog, C., \& Carter, L. (1988). Sex differences in the structure of intelligence: A confirmatory factor analysis. Intelligence, 6, 287-304.

23.Jaeggi, S.M., \& Buschkuehl, M. (2013). Working Memory Training and Transfer: Theoretical and Practical Considerations. University of California, Irvine.

24.Lim, T. K. (1994). Gender-related differences in intelligence: Application of confirmatory factor analysis. Intelligence, 19, 179-192.

25.Lubinski, D. (2004). Introduction to the special section on cognitive abilities: 100 years after Spearman's (1904) 'General intelligence', objectively determined and measured. Journal of Personality and Social Psychology, 86, 96-111.

26. Lynn, R., Allik, J., \& Irwing, P. (2004). Sex differences on three factors identified in Raven's Standard Progressive Matrices. Intelligence, 32, 411-424.

27. Mackintosh, N. J., \& Bennett, E. S. (2005). What do Raven's Matrices measure? An analysis in terms of sex differences. Intelligence, 33, 663-674. 
البنية العاملية للاكاء السائل لاى طلاب كلية التربية جامعة الفيوم د. عائشة على رف عطية

28.McGrew, K. (2006). Revised/Updated Cattell-Horn-Carroll (CHC) Theory of Cognitive Ability Classifications of the WJ III Cognitive and Achievement Tests. Psychometrics, 1-17

29. Raven, J. C., Court, J. H., \& Raven, J. (1998). Manual for Raven's Progressive Matrices and Vocabulary Scales. (Section 4: Advanced Progressive Matrices, Set1 and Set2). London: Lewis.

30. Stepankova, H., Lukavsky, J., Buschkuehl, M., Kopecek, M., Ripova, D., \& Jaeggi, S. M. (2013). The Malleability of Working Memory and Visuospatial Skills: Arandomized Controlled Study in Older Adults. Developmental Psychology. Advance online publication.doi: 10.1037/a0034913

31.Van der Ven, A.H.G.S., \& Ellis, J. L. (2000). A Rasch analysis of Raven's standard progressive matrices. Personality and Individual Differences, 29, 45-64.

32.Vigneau, F., \& Bors, D. A. (2005). Items in context: Assessing the dimensionality of Raven's Advanced Progressive Matrices. Educational and Psychological Measurement, 65, 109-123. 